\title{
¿Diversity of Marine Heatwaves in the South China Sea Regulated by ENSO Phase
}

\author{
KAI LiU, ${ }^{\mathrm{a}, \mathrm{b}, \mathrm{c}, \mathrm{d}}$ KANG XU, ${ }^{\mathrm{e}, \mathrm{c}, \mathrm{f}}$ CONGWEN Zhu, ${ }^{\mathrm{a}}$ and BoQI LiU ${ }^{\mathrm{a}}$ \\ ${ }^{a}$ State Key Laboratory of Severe Weather and Institute of Climate System, Chinese Academy of Meteorological Sciences, Beijing, China \\ ${ }^{\mathrm{b}}$ University of Chinese Academy of Sciences, Beijing, China \\ ${ }^{\mathrm{c}}$ Southern Marine Science and Engineering Guangdong Laboratory (Guangzhou), Guangzhou, China \\ ${ }^{\mathrm{d}}$ National Marine Environmental Forecasting Center, Beijing, China \\ ${ }^{\text {e }}$ State Key Laboratory of Tropical Oceanography, South China Sea Institute of Oceanology, Chinese Academy of Sciences, Guangzhou, \\ China \\ ${ }^{\mathrm{f}}$ Innovation Academy of South China Sea Ecology and Environmental Engineering, Chinese Academy of Sciences, Guangzhou, China
}

(Manuscript received 19 April 2021, in final form 25 October 2021)

\begin{abstract}
Marine heatwaves (MHWs) in the South China Sea (SCS) have dramatic impacts on local ecosystems, fisheries, and aquacultures. Our results show that SCS MHWs were strongly regulated by El Niño-Southern Oscillation (ENSO) with a distinct life cycle during 1982-2018. Based on the ENSO-associated sea surface temperature anomaly (SSTA) warming peaks in the SCS, we can classify SCS MHWs into three categories: El Niño-P1 during the first warming peak of El Niño from September to the following February, El Niño-P2 during the second warming peak of El Niño from the following June to September, and La Niña-P1 during the single warming peak of La Niña from the following February to May. The three types of SCS MHWs are all affected by the lower-level enhanced anticyclone over the western North Pacific (WNP), but their physical mechanisms are quite different. In El Niño-P1, SCS MHWs are mostly induced by enhanced net downward shortwave radiation and reduced latent heat flux loss over the southwestern and northern SCS, respectively. In E1 Niño-P2, SCS MHWs are primarily attributed to weaker entrainment cooling caused by a local enhanced anticyclone and stronger Ekman downwelling in the central-northern SCS. However, in La Niña-P1, SCS MHWs are mainly contributed by the reduced latent heat loss due to the weaker WNP anticyclone centered east of the Philippines on the pentad time scale. The distinct spatial distributions of MHWs show phase locking with ENSO-associated SCS SSTA warming, which provides a potential seasonal forecast of SCS MHWs according to the ENSO phase.
\end{abstract}

KEYWORDS: Atmosphere-ocean interaction; ENSO; Extreme events

\section{Introduction}

Marine heatwaves (MHWs) are climate extremes with prolonged warm sea surface temperatures (SSTs) that can broadly extend up to thousands of kilometers (Waliser 1996; Qin et al. 2007; Hobday et al. 2016; Scannell et al. 2016; Oliver et al. 2018a). MHWs are also referred to as "hot spots" (Waliser 1996), "hot events" (Qin et al. 2007), or "warm blob" (Bond et al. 2015; Di Lorenzo and Mantua 2016). MHWs have devastating and long-term impacts on large-scale ecosystems, fisheries, and aquaculture ecosystems, with subsequent socioeconomic consequences (Frolicher and Laufkotter 2018; Oliver et al. 2018b; Smale et al. 2019). Examples include the mass mortality of abalone off Western Australia (Pearce and Feng 2013), benthic habitat loss along the Mediterranean Sea (Garrabou et al. 2009), and altered human use of fisheries in the northwest Atlantic and off Western Australia (Mills et al. 2013; Caputi et al. 2016). Therefore, a better understanding of the occurrence and development mechanisms of MHWs may benefit seasonal forecasting.

Under recent global warming, many MHWs have been observed in the oceans (Frolicher et al. 2018; Holbrook et al.

\footnotetext{
๑Denotes content that is immediately available upon publication as open access.
}

Corresponding author: Kang Xu, xukang@scsio.ac.cn
2020). Qin et al. (2007) found that 31 MHW events occurred in the tropical oceans during the period of 1993-2003, and most $(68 \%)$ MHW events were clustered in the equatorial western Pacific. The longest-duration MHWs usually occurred in the eastern equatorial Pacific in association with El Niño (Holbrook et al. 2019) and occasionally occurred in the northeast Pacific (Bond et al. 2015) and Tasman Sea marine environments (Oliver et al. 2017).

Some studies have attributed MHWs to local air-sea internal variability (Qin et al. 2007, 2008; Qin and Kawamura 2009, 2010) and large-scale ocean modes of climate variability (Holbrook et al. 2019, 2020). For example, eddy instabilities can change the mixed layer temperature and subsequently give rise to MHWs (Schlegel et al. 2017). Local extreme air-sea coupling can induce MHWs by modulating in situ oceanic conditions (Olita et al. 2007; Bond et al. 2015; Oliver et al. 2017). The propagation of planetary waves in the atmosphere (ocean) also produces MHWs by altering surface winds and cloud cover via remote atmospheric (oceanic) teleconnections (Chen and Qin 2016; Benthuysen et al. 2018; Heidemann and Ribbe 2019; Li et al. 2020). In particular, El Niño-Southern Oscillation (ENSO) has been regarded as the most important factor (Oliver et al. 2018b; Holbrook et al. 2019). Di Lorenzo and Mantua (2016) revealed that the 2014/15 El Niño induced the extreme northeast Pacific Blob event by an El Niño-induced anomalous anticyclone over the North Pacific. Heidemann and Ribbe (2019) found that MHWs on the northeast coast of Australia were closely associated with 
El Niño events peaking in the previous 7 months, while Feng et al. (2013) showed that the MHWs off the coast of western Australia were more related to La Niña conditions.

Several studies have concentrated on extreme MHW events in the marginal seas of China (Li et al. 2019; Wang et al. 2019; Gao et al. 2020; Yan et al. 2020; Yao et al. 2020; Yao and Wang 2021). As a result of the much faster warming rate, MHWs have longer durations and are more frequent with greater extension and intensity in the marginal seas of China (Yao et al. 2020). Thompson et al. (2017) observed a remarkable warming trend in the South China Sea (SCS) since 1997, and SCS MHWs might occur more frequently under global warming (Yao et al. 2020). Xiao et al. (2020) reported that a record-breaking SCS MHW event in 2015 caused severe coral bleaching on the Dongsha Atoll. Yao and Wang (2021) revealed that the anomalous western North Pacific subtropical high modulated by interbasin interactions weakens midwestern South China Sea upwelling and triggers severe summertime MHWs.

Except for some case studies, little attention has been given to the general features of SCS MHWs, especially their interannual variability. ENSO events can modulate SCS SST anomalies (SSTAs) on the interannual time scale via atmospheric Rossby wave responses (Ose et al. 1997; Klein et al. 1999; Wang et al. 2000). El Niño may enhance the anticyclonic anomalies over the western North Pacific (WNP) and warm the SCS through local air-sea interactions (Wang et al. 2000). Associated impacts on the SCS are prolonged by the Indian Ocean capacitor effect after the mature ENSO phase (Xie et al. 2009), as in the extreme case in 2015 (Xiao et al. 2020). Wang et al. (2006) found double warming peaks of the SCS SSTA in the mature phase and the following summer of El Niño events. Some literature has also examined the different responses of the SCS SST to El Niño diversity (Liu et al. 2014; Tan et al. 2016).

Although the SCS SSTA is closely linked to ENSO events, the relationship between the SCS MHWs and ENSO has not yet been sufficiently addressed. This study aimed to investigate the variability in SCS MHWs on an interannual time scale and to explore the mechanisms by which ENSO events regulate MHWs in the SCS. The remainder of the paper is organized as follows. The datasets and methods utilized in this study are briefly introduced in section 2 . Section 3 demonstrates the statistical characteristics of MHWs in the SCS. The relationships between SCS MHWs and ENSO are clarified in section 4. Section 5 explains the potential mechanisms by which ENSO influences SCS MHWs. Finally, a discussion and summary are presented in section 6 .

\section{Data and methodology}

\section{a. Data}

Daily SSTs with a horizontal resolution of $0.25^{\circ} \times 0.25^{\circ}$ were extracted from the NOAA Optimum Interpolation Sea Surface Temperature (OISST version 2) dataset (Reynolds et al. 2007). Daily atmospheric reanalysis data, including $10-\mathrm{m}$ wind, total cloud cover, surface net shortwave radiation, net longwave radiation, latent heat flux, and sensible heat flux, were obtained from the National Centers for Environmental Prediction-Department of Energy Reanalysis 2 (NCEP-DOE R2) products (Kanamitsu et al. 2002). In these datasets, surface variables are stored on a global T62 Gaussian grid, while isobaric variables are available at a horizontal resolution of $2.5^{\circ} \times 2.5^{\circ}$ and extend from 1000 to 10 $\mathrm{hPa}$ with 17 vertical pressure levels. Due to the lack of daily subsurface ocean data, pentad subsurface ocean data from the NCEP Global Ocean Data Assimilation System (GODAS; Behringer 2007) were applied in this study. The analysis period of all the above datasets covers 1982-2018, and anomalies of all variables were calculated as the deviation from the corresponding mean seasonal cycle. Following the criterion of NOAA, an El Niño (La Niña) event was defined by an oceanic Niño index (ONI; https:// ggweather.com/enso/oni.htm) greater (less) than or equal to $0.5^{\circ} \mathrm{C}$ $\left(-0.5^{\circ} \mathrm{C}\right)$ for at least five consecutive overlapping seasons.

\section{b. Methods}

Hobday et al. (2016) qualitatively defined an MHW as a prolonged discrete anomalously warm water event in a particular location. Following this definition, the 90th percentile was first calculated for each calendar day using daily SSTs within an 11day window centered on the data across all years (1982-2018) within the climatology period and smoothed by applying a 31day moving average. Thus, MHWs in the SCS were identified when daily SSTs were above the climatological seasonally varying 90th percentile for at least five consecutive days. Note that two successive events with a break of less than two days were combined and identified as a single joint event. Additionally, five MHW metrics were used in this study: duration (cumulative days from the start date to end date), maximum intensity (maximum SSTA during an MHW), mean intensity (mean SSTA during an MHW), cumulative intensity (sum of daily SSTAs measured as ${ }^{\circ} \mathrm{C}$ days), and growth rate (SSTA increase rate during the period from the beginning of the MHW to its maximum intensity measured as ${ }^{\circ} \mathrm{C}$ day ${ }^{-1}$ ).

A mixed layer heat budget analysis was performed to explore the relative contributions of physical processes to ENSOrelated MHWs in different stages. The mixed layer temperature budget can be expressed as the following equation:

$$
\underbrace{\frac{\partial T_{m}^{\prime}}{\partial t}}_{\text {Tend }}=\underbrace{\frac{Q^{\prime}}{\rho C_{p} h_{m}}}_{\text {Qnet }}-\bar{u} \underbrace{\frac{\partial T_{m}^{\prime}}{\partial x}}_{\text {ZAdv }}-u^{\prime} \underbrace{\frac{\partial T_{m}^{\prime}{ }_{m}}{\partial x}}_{\text {ZAdva }}-u^{\prime} \underbrace{\frac{\partial T_{m}^{\prime}}{\partial x}}_{\text {ZAdv' }}-\bar{v} \underbrace{\frac{\partial T_{m}^{\prime}}{\partial y}}_{\text {MAdv }}-v^{\prime} \underbrace{\frac{\partial \bar{T}_{m}}{\partial y}}_{\text {MAdva }}-v^{\prime} \underbrace{\frac{\partial T_{m}^{\prime}}{\partial y}}_{\text {MAdv' }}-\overline{w_{e}} \frac{\left(T_{m}-T_{d}\right)^{\prime}}{\underbrace{h_{m}}_{\text {VAdv }}}-w_{e}^{\prime} e_{e}^{\frac{\overline{T_{m}}-T_{d}}{h_{m}}}-\underbrace{h_{m}}_{\text {VAdva }} w_{e}^{\frac{\left(T_{m}-T_{d}\right)^{\prime}}{h_{m}}}+R
$$


where $T_{m}, u$, and $v$ represent the ocean temperature and zonal and meridional ocean current velocities averaged over the mixed layer depth, respectively. We used a spatially and temporally varying $h_{m}$ defined as the mixed layer depth where ocean temperature is $0.5^{\circ} \mathrm{C}$ lower than the surface value. The terms $w_{e}$ and $T_{d}$ are the vertical ocean current velocity and the water temperature at a depth of $10 \mathrm{~m}$ below the bottom of the mixed layer, respectively. The net surface heat flux anomaly $\left(Q^{\prime}\right)$ is the summation of the net downward shortwave radiation (SWR), net upward longwave radiation (LWR), sensible heat flux (SHF), and latent heat flux (LHF) at the ocean surface, and a positive value indicates surface heat flux into the ocean. The terms $\rho=1025 \mathrm{~kg} \mathrm{~m}^{-3}$ and $C_{p}=$ $4000 \mathrm{~J} \mathrm{~kg}^{-1} \mathrm{~K}^{-1}$ are the reference density of seawater and the specific heat of seawater, respectively. Bars and primes denote climatologic mean variables and anomaly departures from climatologic means, respectively.

The left-hand side of Eq. (1) is the mixed layer ocean temperature tendency (Tend). On the right-hand side, Qnet is the net surface heat flux term, ZAdv (MAdv and VAdv) is the zonal (meridional and vertical) advection of the anomalous temperature by the mean velocity, ZAdva (MAdva and VAdva) is the zonal (meridional and vertical) advection of the mean temperature by the anomalous velocity, $\mathrm{ZAdv}^{\prime}\left(\mathrm{MAdv}^{\prime}\right.$ and $\left.\mathrm{VAdv}^{\prime}\right)$ is the nonlinear zonal (meridional and vertical) advection of the anomalous temperature by the anomalous velocity, and $R$ represents the residual term.

\section{Statistical analyses of MHWs in the SCS}

According to the definition of MHWs, 61 MHW events were identified in the SCS $\left(0^{\circ}-25^{\circ} \mathrm{N}, 100^{\circ}-120^{\circ} \mathrm{E}\right)$ during 1982-2018 (Table 1). In addition to these 61 events, other MHWs might still be found in subregions of the SCS because the definition was based on the average SST of the entire SCS region in this study. Fifty-five of the $61 \mathrm{MHWs}$ occurred after 1996, when the SST exhibited a remarkable warming trend in the SCS (Thompson et al. 2017). The average duration of SCS MHWs was 18.13 days (Fig. 1a), and their mean intensity was $+0.77^{\circ} \mathrm{C}$, with a maximum intensity of $+0.93^{\circ} \mathrm{C}$ (Fig. 1b). The mean growth rate was $+0.057^{\circ} \mathrm{C} \mathrm{day}^{-1}$ (Fig. 1d). The most extreme MHW in winter 2016 reached a maximum intensity of $+1.58^{\circ} \mathrm{C}$ with a cumulative intensity of $37.07^{\circ} \mathrm{C}$ days from 1 January to 2 February (Table 1). Another extreme occurred in the winter of 1997/98, which showed the longest duration of 101 days and the largest cumulative intensity of $101.70^{\circ} \mathrm{C}$ days (Table 1). These two events have previously been ascribed to the super El Niño event (Xiao et al. 2018, 2020). High correlations between the duration and the cumulative intensity (the correlation coefficient was +0.98 ) and growth rate (the correlation coefficient was -0.35 ) suggest that SCS MHWs with higher cumulative intensities generally have longer durations but develop more slowly, and vice versa.
Statistically, approximately 1.65 MHWs with a duration of 30 days occurred each year in the SCS. The highest frequency of MHWs occurred in 2010, with eight events, followed by six MHWs in 2015 and five MHWs in 2016. Regarding the total duration of MHWs, the longest events took place in 1998, followed by 2015, 2010, and 2016 in descending order. The average duration of MHWs was longer than 3 months in 4 years (figure omitted). Notably, the frequency of SCS MHWs exhibited an increasing tendency, corresponding to ENSO regime changes (Xu et al. 2019b). Most of the 61 identified MHWs were related to El Niño events, although some may have occurred in the La Niña phase. After removing the effects of the linear trend of the SST in the SCS, MHWs became more frequent before 1996, while the average duration was obviously reduced, with weakened maximum and cumulative intensities, which denotes that the warming trend plays an important role in SCS MHW metrics.

Figure 2 shows the seasonal distribution of SCS MHWs after removing extremes with durations greater than 50 days to investigate the seasonality of SCS MHWs. Despite the lowest frequency (only 10 events) of MHWs occurring in winter, winter events experience the second-longest life cycle of 12.3 days (Fig. 2a) and show a maximum intensity of $+1.13^{\circ} \mathrm{C}$ (Fig. 2b), resulting in the strongest cumulative intensity (Fig. 2c). The life cycle of spring MHWs is shorter (Fig. 2a) but shows the second-highest maximum intensity (Fig. 2b), consequently giving rise to the rapidest growth rate (Fig. 2d). In addition, MHW metrics in summer have the smallest dispersions among the four seasons, indicating that summer SCS MHWs tend to be stable, which is consistent with their relatively longest duration (Fig. 2a) and lowest growth rate (Fig. 2d).

Figure 3 displays the composite daily SSTAs in the SCS on all days when MHWs occurred in the four seasons to investigate seasonally varying MHW-related SSTAs. Seasonal SCS SSTAs associated with MHWs also exhibit different spatial patterns. SSTAs during boreal summer and winter are warmer than their counterparts in boreal spring and autumn (Fig. 3). Summer MHWs are characterized by warmer-than-normal SSTAs in the northern-central SCS, with the warmest center concentrated in the central SCS (Fig. 3b), whereas those of their winter counterparts are mainly observed in the western SCS, which features two warming SST centers located south of Hainan Island and south of Vietnam (Fig. 3d). In spring, warmer MHWrelated SSTAs are located in the Beibu Gulf, west of the Luzon Strait, and along the Vietnam coast (Fig. 3a). However, autumn MHWs mainly occur in the northwestern SCS (Fig. 3c). Note that the extreme MHWs have little interference effect in the composite results (not shown). These statistical results indicate that SCS MHWs exhibit remarkable seasonality. Due to the close relationship between SCS MHWs and ENSO (Fig. 1), we infer that the possible cause of MHW seasonality is the phase locking of the ENSO-induced WNP anticyclone anomaly revealed by previous studies (Wang et al. 2000; Wu et al. 2010; Stuecker et al. 2015). 
TABLE 1. Summary of the properties and metrics of SCS MHWs during 1982-2018. The periods in bold (italic) font indicates an SCS MHW associated with an El Niño (a La Niña) event.

\begin{tabular}{|c|c|c|c|c|c|c|}
\hline No. & Period & Duration (days) & $\begin{array}{c}\text { Maximum } \\
\text { intensity }\left({ }^{\circ} \mathrm{C}\right)\end{array}$ & $\begin{array}{c}\text { Mean intensity } \\
\left({ }^{\circ} \mathrm{C}\right)\end{array}$ & $\begin{array}{c}\text { Cumulative } \\
\text { intensity } \\
\left({ }^{\circ} \mathrm{C} \text { days }\right)\end{array}$ & $\begin{array}{l}\text { Rate of onset } \\
\left(0.1^{\circ} \mathrm{C}_{\text {day }}{ }^{-1}\right)\end{array}$ \\
\hline 1 & 12-26 Sep 1983 & 15 & 0.69 & 0.58 & 8.81 & 0.44 \\
\hline 2 & 10 Oct-3 Nov 1987 & 25 & 1.26 & 0.86 & 21.57 & 0.73 \\
\hline 3 & 17-25 Nov 1987 & 9 & 0.80 & 0.70 & 6.36 & 0.49 \\
\hline 4 & 5-9 Feb 1988 & 5 & 0.94 & 0.80 & 4.01 & 1.59 \\
\hline 5 & 4-18 Sep 1988 & 15 & 0.89 & 0.69 & 10.49 & 0.51 \\
\hline 6 & 5-20 Jul 1996 & 16 & 0.86 & 0.71 & 11.42 & 0.73 \\
\hline 7 & 19-23 Mar 1997 & 5 & 0.94 & 0.83 & 4.15 & 0.92 \\
\hline 8 & 10-15 Oct 1997 & 6 & 0.63 & 0.59 & 3.56 & 0.59 \\
\hline 9 & 19-28 Oct 1997 & 10 & 0.89 & 0.73 & 7.36 & 0.56 \\
\hline 10 & 27 Dec 1997-6 Apr 1998 & 101 & 1.53 & 1.00 & 101.7 & 0.14 \\
\hline 11 & 16-25 May 1998 & 10 & 1.32 & 0.97 & 9.76 & 0.11 \\
\hline 12 & 16 Jun-6 Jul 1998 & 21 & 1.05 & 0.81 & 17.05 & 0.58 \\
\hline 13 & 13 Jul-14 Oct 1998 & 94 & 1.30 & 0.82 & 77.40 & 0.13 \\
\hline 14 & 26 Jan-5 Feb 1999 & 11 & 1.18 & 0.89 & 9.84 & 0.81 \\
\hline 15 & 18 Mar-4 Apr 1999 & 18 & 1.01 & 0.82 & 14.80 & 0.36 \\
\hline 16 & 8-12 Apr 2001 & 5 & 0.83 & 0.74 & 3.74 & 0.88 \\
\hline 17 & 17-23 Apr 2001 & 7 & 0.92 & 0.74 & 5.22 & 1.13 \\
\hline 18 & 4-9 May 2001 & 6 & 0.90 & 0.79 & 4.77 & 0.77 \\
\hline 19 & 27 Jun-3 Jul 2002 & 7 & 0.68 & 0.63 & 4.47 & 0.47 \\
\hline 20 & 16 Dec 2002-5 Jan 2003 & 21 & 1.15 & 1.00 & 21.02 & 0.42 \\
\hline 21 & 9-14 Nov 2005 & 6 & 0.83 & 0.71 & 4.28 & 0.75 \\
\hline 22 & 19 Nov-2 Dec 2006 & 14 & 1.05 & 0.89 & 12.46 & 0.50 \\
\hline 23 & 15-28 Jun 2007 & 14 & 0.76 & 0.65 & 9.22 & 0.34 \\
\hline 24 & 24-30 Jul 2007 & 7 & 0.58 & 0.54 & 3.81 & 0.48 \\
\hline 25 & 18 Oct-10 Nov 2008 & 24 & 0.92 & 0.76 & 18.33 & 0.22 \\
\hline 26 & 4-8 Mar 2009 & 5 & 0.92 & 0.82 & 4.10 & 1.31 \\
\hline 27 & 31 Jan-17 Feb 2010 & 18 & 1.15 & 0.91 & 16.47 & 0.61 \\
\hline 28 & 23 Feb-9 Mar 2010 & 15 & 1.28 & 1.05 & 15.85 & 0.50 \\
\hline 29 & 8-12 Мay 2010 & 5 & 0.74 & 0.66 & 3.33 & 1.08 \\
\hline 30 & 18 May-2 Jun 2010 & 16 & 0.97 & 0.78 & 12.63 & 0.93 \\
\hline 31 & 11-26 Jun 2010 & 16 & 0.76 & 0.69 & 11.10 & 0.33 \\
\hline 32 & 4-23 Jul 2010 & 20 & 0.85 & 0.73 & 14.64 & 0.34 \\
\hline 33 & 12-28 Aug 2010 & 17 & 0.74 & 0.58 & 9.99 & 0.46 \\
\hline 34 & 21 Sep-19 Oct 2010 & 29 & 0.97 & 0.71 & 20.79 & 0.83 \\
\hline 35 & 19-23 Mar 2012 & 5 & 0.76 & 0.73 & 3.68 & 0.21 \\
\hline 36 & 21 Nov-26 Dec 2012 & 36 & 1.10 & 0.91 & 33.07 & 0.17 \\
\hline 37 & 23 Mar-8 Apr 2013 & 17 & 1.01 & 0.88 & 14.99 & 0.26 \\
\hline 38 & 8-24 May 2013 & 17 & 0.86 & 0.75 & 12.88 & 0.36 \\
\hline 39 & 31 May-15 Jun 2013 & 16 & 0.95 & 0.72 & 11.58 & 0.45 \\
\hline 40 & 17 Apr-5 May 2014 & 19 & 0.94 & 0.76 & 14.51 & 0.23 \\
\hline 41 & 16 May 2014-12 June 2014 & 28 & 1.25 & 0.99 & 27.75 & 0.44 \\
\hline 42 & 20-27 Aug 2014 & 8 & 0.68 & 0.58 & 4.67 & 0.62 \\
\hline 43 & 31 Aug-4 Sep 2014 & 5 & 0.54 & 0.51 & 2.56 & 0.44 \\
\hline 44 & 23 Oct-4 Nov 2014 & 13 & 0.79 & 0.68 & 8.84 & 0.35 \\
\hline 45 & 27 Nov-5 Dec 2014 & 9 & 0.91 & 0.84 & 7.58 & 0.60 \\
\hline 46 & 15-23 May 2015 & 9 & 0.87 & 0.77 & 6.98 & 0.65 \\
\hline 47 & 8-22 Jun 2015 & 15 & 0.88 & 0.75 & 11.36 & 0.26 \\
\hline 48 & 28 Jul-6 Aug 2015 & 10 & 0.76 & 0.66 & 6.61 & 0.70 \\
\hline 49 & 13-20 Aug 2015 & 8 & 0.62 & 0.57 & 4.59 & 0.64 \\
\hline 50 & 1 Sep-17 Oct 2015 & 47 & 1.15 & 0.81 & 38.18 & 1.58 \\
\hline 51 & 25 Oct-27 Dec 2015 & 66 & 1.37 & 1.00 & 66.38 & 0.19 \\
\hline 52 & 2 Jan-2 Feb 2016 & 32 & 1.58 & 1.15 & 37.07 & 0.40 \\
\hline 53 & 22 Apr-27 May 2016 & 36 & 0.93 & 0.78 & 28.16 & 0.20 \\
\hline 54 & 19-25 Jun 2016 & 7 & 0.66 & 0.62 & 4.37 & 0.30 \\
\hline 55 & 1 Jul-2 Aug 2016 & 33 & 0.95 & 0.70 & 23.25 & 0.16 \\
\hline 56 & 17-26 Nov 2016 & 10 & 1.00 & 0.83 & 8.38 & 0.77 \\
\hline
\end{tabular}




\begin{tabular}{|c|c|c|c|c|c|c|}
\hline No. & Period & Duration (days) & $\begin{array}{c}\text { Maximum } \\
\text { intensity }\left({ }^{\circ} \mathrm{C}\right)\end{array}$ & $\begin{array}{l}\text { Mean intensity } \\
\left({ }^{\circ} \mathrm{C}\right)\end{array}$ & $\begin{array}{c}\text { Cumulative } \\
\text { intensity } \\
\left({ }^{\circ} \mathrm{C} \text { days }\right)\end{array}$ & $\begin{array}{l}\text { Rate of onset } \\
\left(0.1^{\circ} \mathrm{C} \text { day }^{-1}\right)\end{array}$ \\
\hline 57 & 11-21 Feb 2017 & 11 & 0.90 & 0.79 & 8.78 & 1.46 \\
\hline 58 & 29 Sep-9 Oct 2017 & 11 & 0.74 & 0.65 & 7.23 & 0.39 \\
\hline 59 & 21-28 Мay 2018 & 8 & 0.70 & 0.64 & 5.17 & 0.43 \\
\hline 60 & 5-11 Dec 2018 & 7 & 0.89 & 0.87 & 6.10 & 0.75 \\
\hline 61 & 19-28 Dec 2018 & 10 & 1.06 & 0.89 & 8.98 & 0.93 \\
\hline Mean & & 18.13 & 0.93 & 0.77 & 15.05 & 0.57 \\
\hline
\end{tabular}

\section{Relationships between ENSO and MHWs in the SCS}

ENSO events have a large influence on the seasonal and monthly time scales of SSTAs in the SCS (Qu et al. 2004; Wang et al. 2006; Liu et al. 2014; Tan et al. 2016). According to the criteria of NOAA CPC, $12 \mathrm{El}$ Niño and 14 La Niña events were identified during the period of 1982-2018. First, we focused on the ENSO events associated with SCS MHWs (Table 1); therefore, the El Niño (1982/83, 1987/88, 1997/98, 2002/03, 2006/07, 2009/10, 2014/15, and 2015/16) and La Niña (1998/99, 2000/01, 2008/09, 2011/12, 2016/17, and 2017/18) years were selected in this study. Fifty-two of the 61 MHWs were related to El Niño or La Niña events (Fig. 1 and Table 1), implying a critical role of ENSO in the occurrence of SCS MHWs on an interannual time scale.
In El Niño events, the seasonal evolution of the 10-day running-mean SSTA exhibits a prominent double warming peak in the SCS. The first warming peak appears in the mature phases of El Niño (D[0]JF[1], where [0] indicates the onset year and [1] indicates the following year), whereas the second peak emerges in the decay phase of El Niño (JJA[1]) (Fig. 4a), which is consistent with the monthly SST-based results revealed by Wang et al. (2006). According to the seasonal evolution of the 120-day running SSTA, this SSTA warming in the SCS peaks in the following January (Jan[1]) and August (Aug[1]) (Fig. 4a). Upon excluding the effects of SCS MHWs, the double warming peak in the SCS still exists, but its magnitude is markedly decreased (see the blue solid curve in Fig. 4a). Therefore, El Niño-induced SST warming peaks provide a favorable background for MHWs in the SCS,

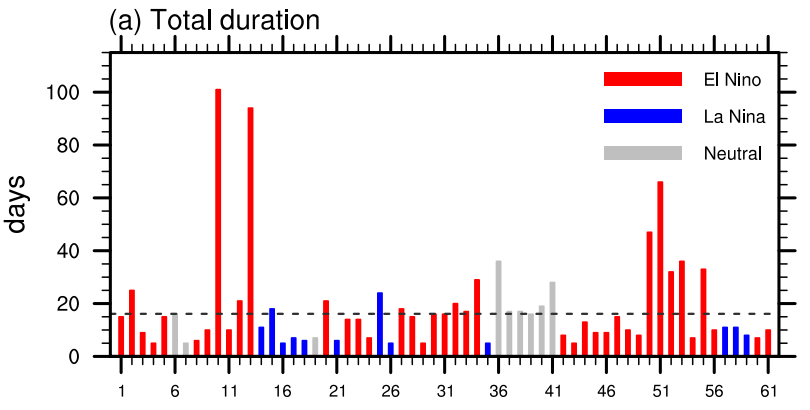

(b) Max intensity
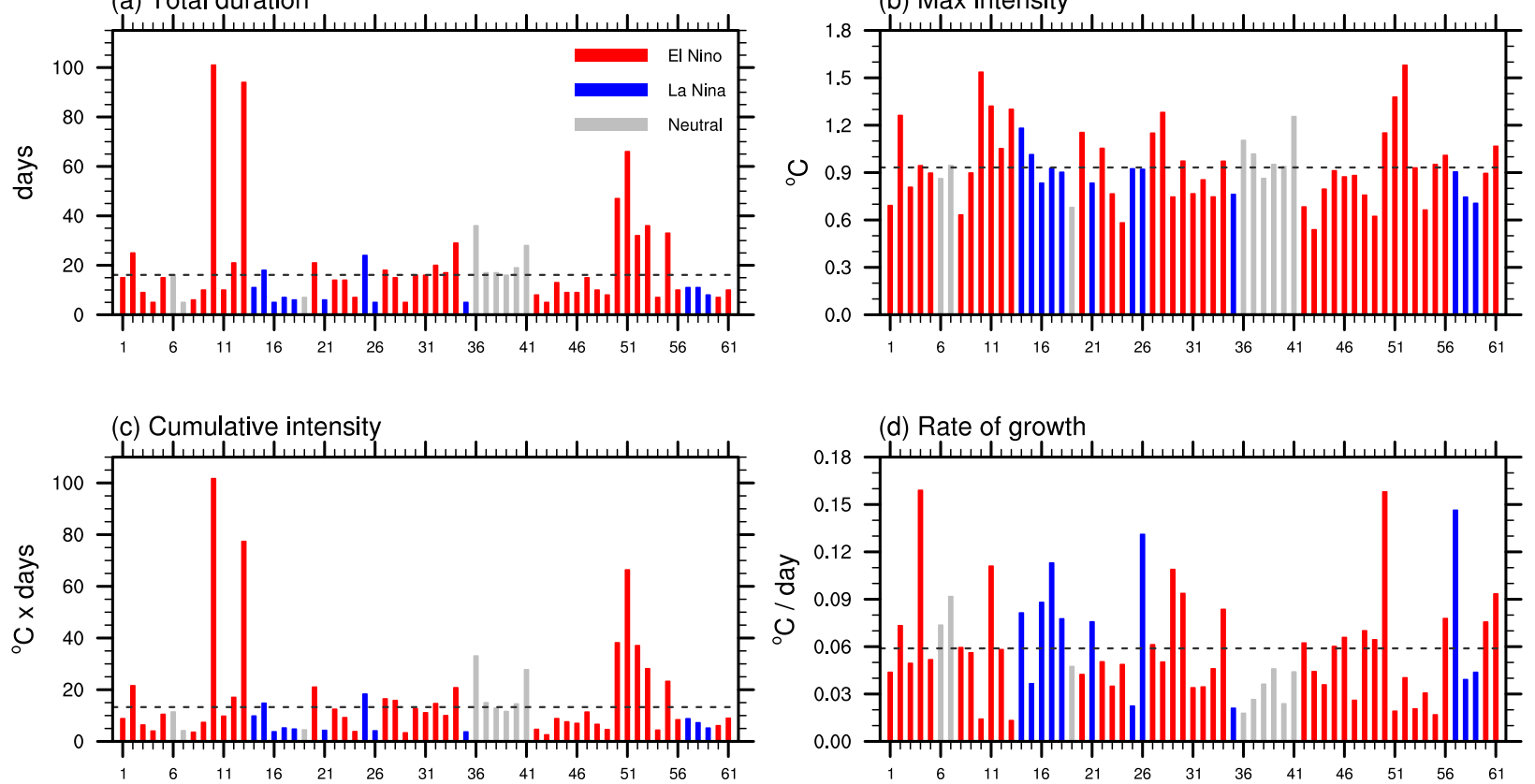

(d) Rate of growth

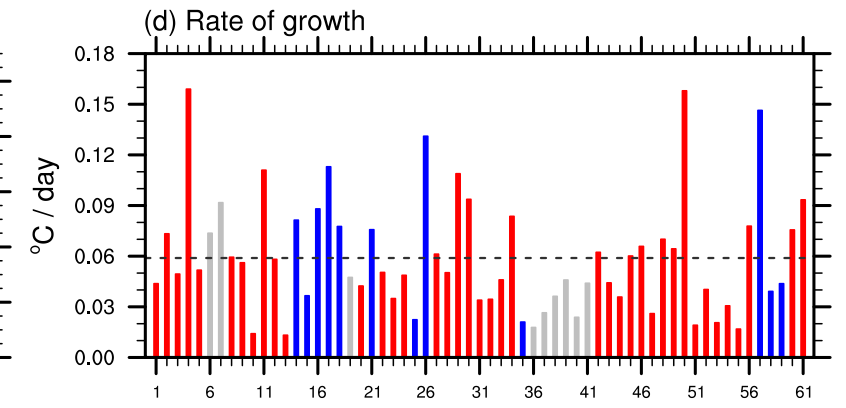

FIG. 1. Statistics of the SCS MHW metrics including (a) total duration (units: days), (b) maximum intensity (units: ${ }^{\circ} \mathrm{C}$ ), (c) cumulative intensity (units: ${ }^{\circ} \mathrm{C}$ days), and (d) growth rate (units: ${ }^{\circ} \mathrm{C}$ day ${ }^{-1}$ ) for the period of 1982-2018. The horizontal axis represents $61 \mathrm{MHW}$ events during 1982-2018, and gray dashed lines indicate the mean metrics of all the MHWs. Red (blue and gray) bars indicate the MHWs associated with El Niño (La Niña and neutral) events. More detailed information on the SCS MHWs can be seen in Table 1. 
(a) Total duration

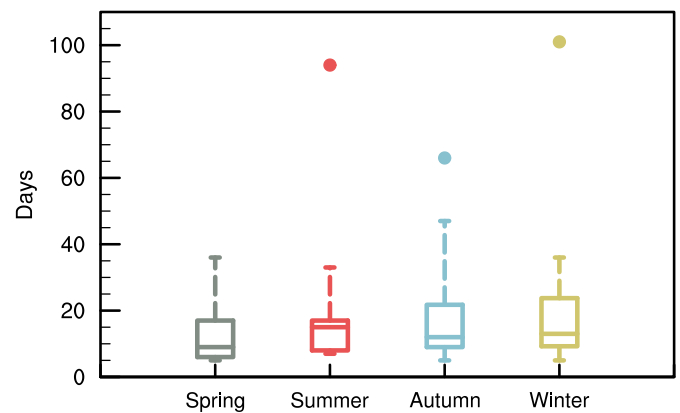

(c) Cumulative intensity

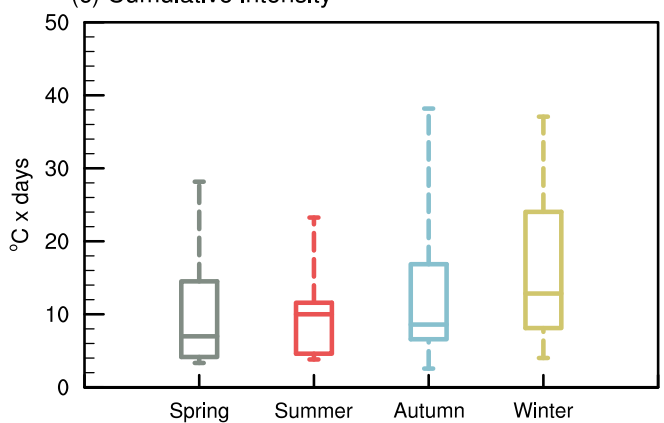

(b) Max intensity

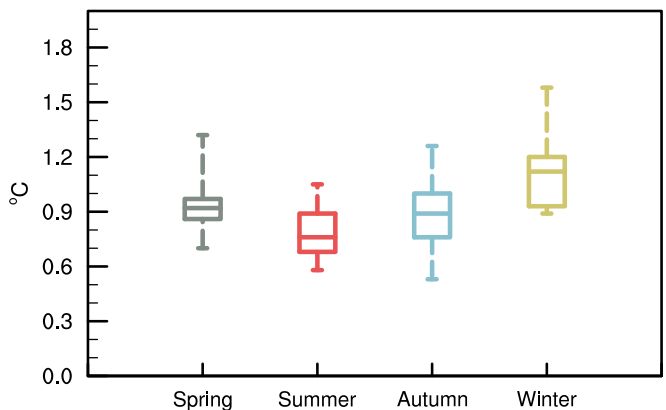

(d) Rate of growth

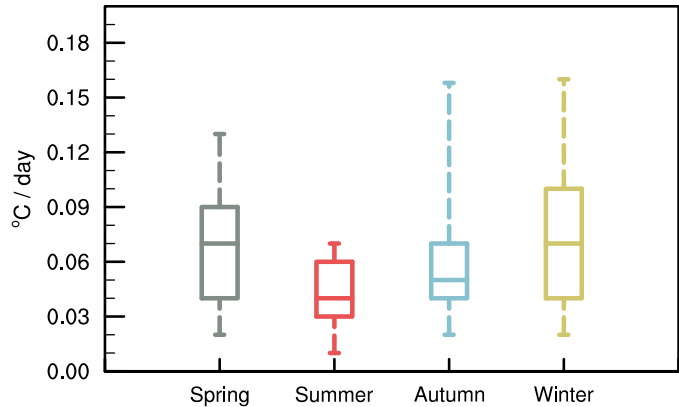

FIG. 2. Boxplots of the seasonal (a) total duration (units: days), (b) maximum intensity (units: ${ }^{\circ} \mathrm{C}$ ), (c) cumulative intensity (units: ${ }^{\circ} \mathrm{C}$ days), and (d) growth rate (units: ${ }^{\circ} \mathrm{C}$ day ${ }^{-1}$ ) of SCS MHWs after removing extremes [marked by the dots in (a)] with durations greater than 50 days.

which can in turn enhance the double-peak warming. In contrast, SCS SSTAs during La Niña events are only characterized by a single warming peak in the following spring (Fig. 4b). The duration and intensity of La Niña-related SCS warming are much shorter and weaker than those of El Niño warming. The La Niña-related warming peak occurs in the following March (Mar[1]), with an average SSTA of $+0.46^{\circ} \mathrm{C}$. The warming peak is also remarkably weakened without MHWs (Fig. 4b). This result suggests that the SCS warming associated with La Niña events is also conducive to MHWs.

Both El Niño and La Niña can substantially modulate SCS SST warming with distinct peak timings and intensities. However, there are large uncertainties in the SCS warming peak time associated with ENSO events (Fig. 4). After selecting the episodes of ENSO-related SCS SST warming peaks, we divided the $52 \mathrm{MHWs}$ into three categories: 24 MHWs that appeared during the first SST warming peak after El Niño events from September(Sep[0]) to the following February (Feb[1]) (hereafter referred to as El Niño-P1), 16 MHWs that occurred during the second warming peak from the following June (Jun[1]) to September (Sep[1]) (hereafter referred to as El Niño-P2), and the remaining 12 cases that occurred during the warming peak of La Niña events from the following February (Feb[1]) to May (May[1]) (hereafter referred to as La Niña-P1).

Figure 5 shows the statistical analyses of SCS MHWs in the three categories after removing extremes with durations greater than 50 days. SCS MHWs in El Niño-P1 exhibit the strongest maximum intensity, while those in El Niño-P2 are weakest (Fig. 5b), which is consistent with the amplitudes of the ENSO-related SST warming peaks (see again Fig. 4). The duration of MHWs in El Niño-P2 is much longer than that in El Niño-P1 (Fig. 5a); however, MHWs in La Niña-P1 generally show the shortest life cycles of less than 10 days (Fig. 5a), with the weakest cumulative intensities (Fig. 5c) and fastest growth rates (Fig. 5d). Therefore, the metrics of SCS MHWs in El Niño-P1, El Niño-P2 and La Niña-P1 show seasonal phase locking (Fig. 2) corresponding to the varied warming peaks of ENSO in summer, winter, and spring.

The spatial distribution of SSTAs in the SCS is quite different in the El Niño-P1, El Niño-P2, and La Niña-P1 categories (Fig. 6). In El Niño-P1, warming SSTAs are located in the southwestern SCS (Fig. 6a), similar to the first-peak SSTA warming pattern of El Niño (not shown). However, in El Niño-P2, the warming SSTA center shifts northeastward and is enhanced in the central-northern SCS (Fig. 6b), consistent with the secondpeak warming pattern of El Niño. In La Niña-P1, there are three warming centers located in the Beibu Gulf, west of the Luzon Strait, and along the Vietnam coast (Fig. 6c). This result is similar to the spring pattern of MHW-related SSTAs (Fig. 3a) corresponding to SCS warming in La Niña-P1. Therefore, most MHWs in the SCS are regulated by ENSO-associated SST warming on an interannual time scale, and the diversity of SCS MHWs can be regarded as the distinct response of local SSTAs to the warming peaks and phases of ENSO. 
(a) Spring

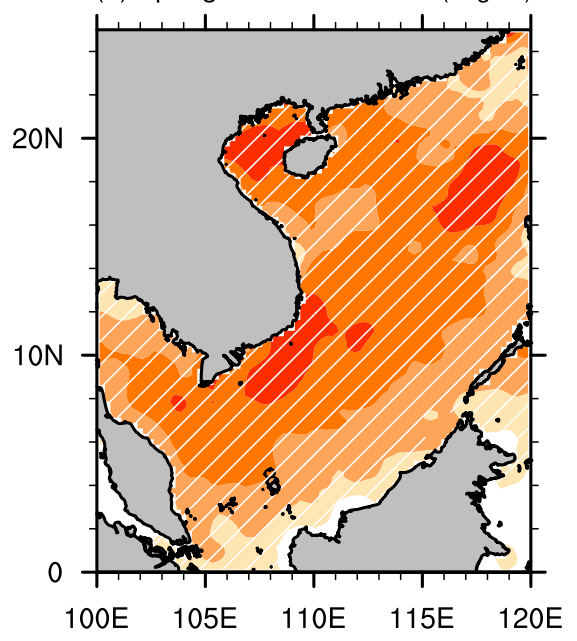

(c) Autumn

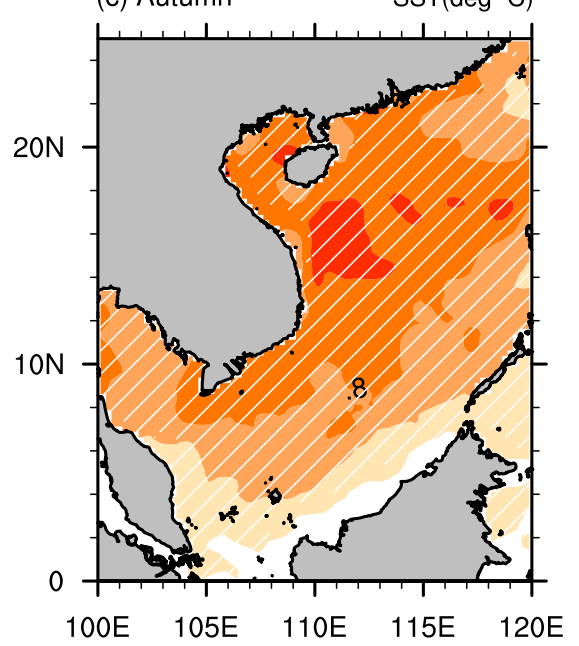

(b) Summer

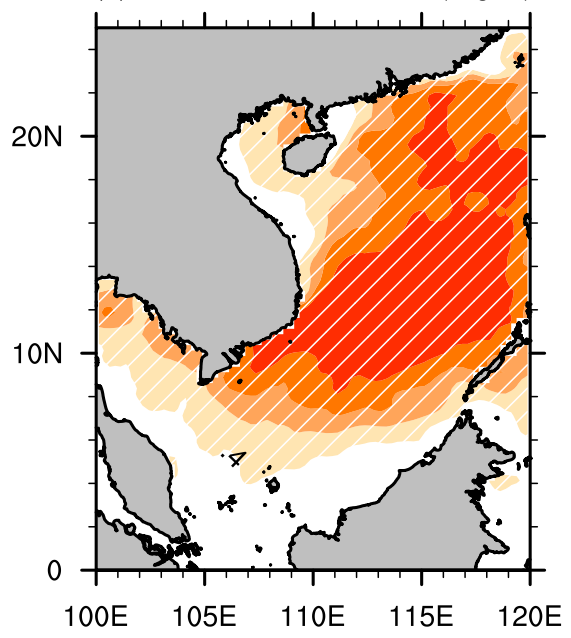

(d) Winter

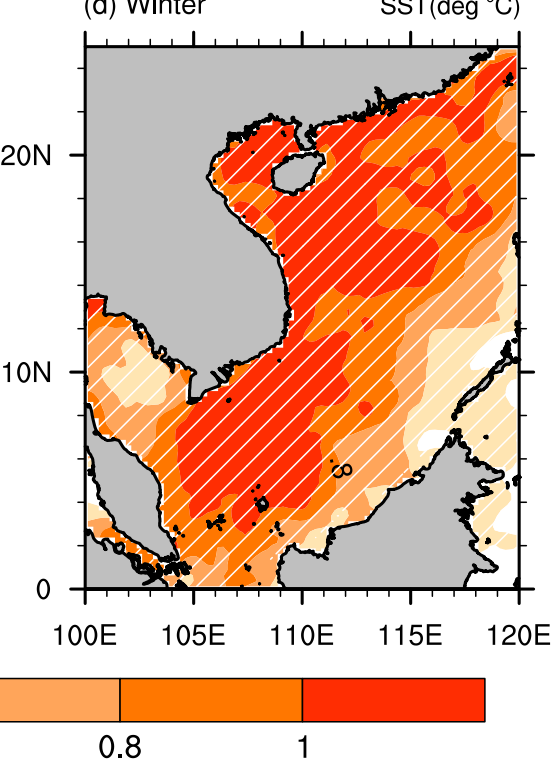

FIG. 3. Composite daily SSTAs (shading; ${ }^{\circ} \mathrm{C}$ ) in the SCS for MHWs occurring in boreal (a) spring, (b) summer, (c) autumn, and (d) winter. White oblique lines indicate SST anomalies that are statistically significant at the $90 \%$ confidence level.

\section{Physical mechanisms of MHWs in the SCS}

\section{a. Mixed layer heat budget analysis}

To quantify the contributions of dynamic and thermodynamic processes to the diversity of SCS MHWs, we employed a mixed layer ocean temperature budget analysis of averaged SCS temperatures $\left(0^{\circ}-25^{\circ} \mathrm{N}, 100^{\circ}-120^{\circ} \mathrm{E}\right)$ based on the pentad GODAS dataset [see Eq. (1)]. Here, we mainly focus on the mixed layer temperature tendencies of SCS MHWs during the growth period spanning from the beginning of the MHW to its maximum intensity. Note that we uniformly expanded the growth period forward by one pentad if the growth period was less than 5 days since the formation of MHWs is a gradually increasing process. The mixed layer temperature tendencies were approximately close to the sums of the surface heat flux and three-dimensional (3D) ocean advection terms, indicating that all the mixed layer heat budget analyses were balanced despite the uncertainties in surface heat fluxes and oceanic subgrid processes. The results show that mixed layer ocean temperature warming is mainly contributed by the net surface heat flux term, while the sum of 3D ocean advections has a smaller warming effect (Fig. 7a). In El Niño-P1 and La Niña$\mathrm{P} 1$, the net surface heat flux term is the most important contributor, whereas those of all 3D ocean advections are almost negligible. However, this is remarkably different from the situation during El Niño-P2. In addition to the net surface heat 
(a) SCS SSTA associated with EI Nino

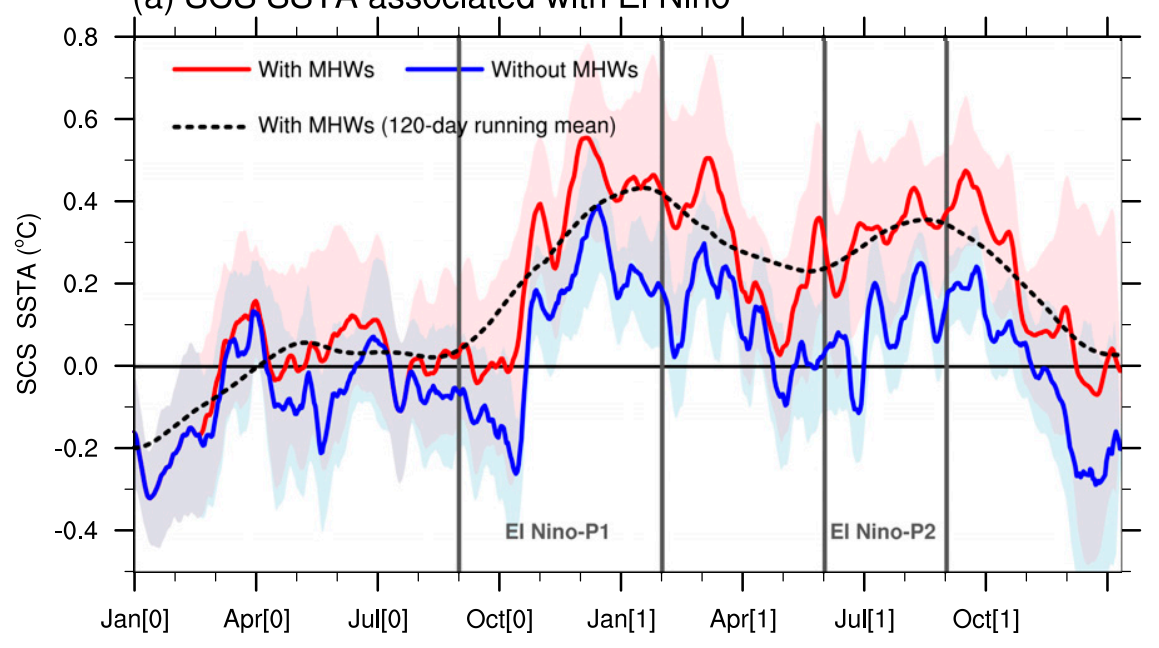

(b) SCS SSTA associated with La Nina

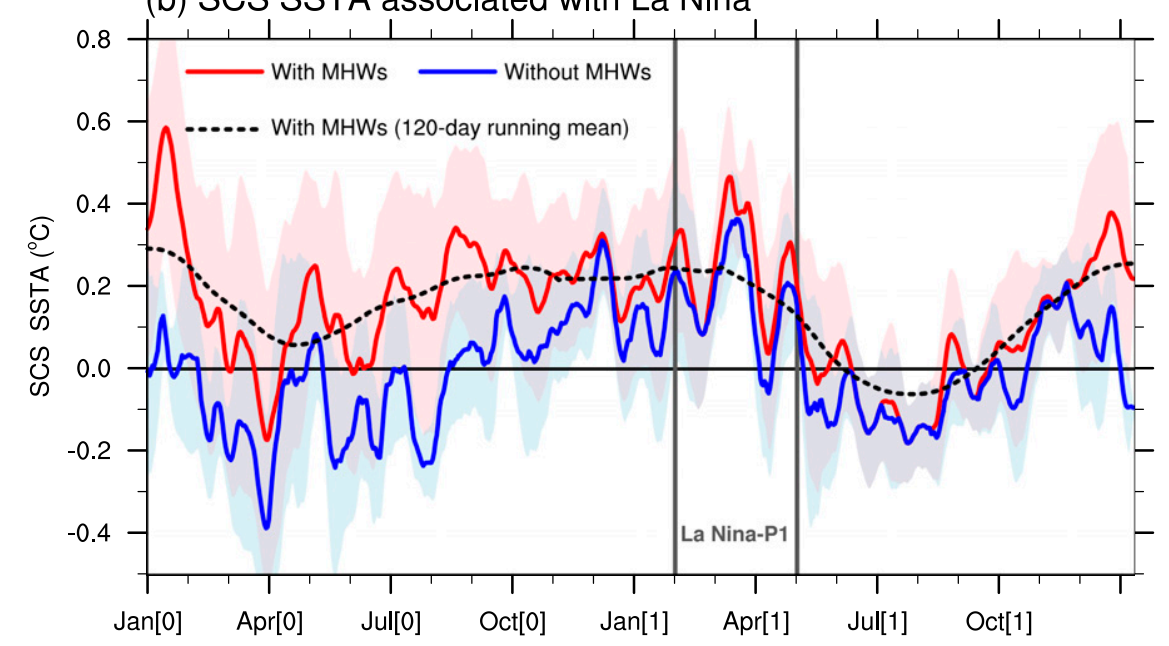

FIG. 4. Time evolution of the 10-day running-mean SCS SSTA (red solid curves; unit: ${ }^{\circ} \mathrm{C}$ ) associated with SCS MHWs during the life cycle of (a) El Niño and (b) La Niña events. The time axis is from January of the onset year (Jan[0]) to December of the following year (Dec[1]). The blue solid curves denote the composite 10-day running-mean SSTA after removing the effects of SCS MHWs, and the black dashed curves represent the 120-day running-mean SSTA. Red (blue) shaded regions indicate the standard deviation of composite SCS SSTAs associated with (not associated with) MHWs during El Niño events in (a) and La Niña events in (b).

flux term, the advection of the mean temperature by the anomalous vertical velocity (VAdva) provides a larger contribution to the temperature growth of SCS MHWs in El NiñoP2 (Fig. 7a).

The effect of the net surface heat flux term in the three categories is always positive, showing that it is the most important factor responsible for MHWs in the SCS. We further decompose the net surface heat flux term into the net downward SWR, net upward LWR, SHF, and LHF terms (Fig. 7b). The dominant thermodynamic heating over the SCS in El Niño-P1 and $\mathrm{El}$ Niño-P2 is mainly contributed by the joint effects of the net downward SWR and LHF anomalies, while the largest contributor in La Niña-P1 is the LHF anomaly.

\section{b. Contributions of anomalous atmospheric and oceanic circulations}

During El Niño-P1, an anomalous lower-level anticyclone is observed over the Indo-China Peninsula to the WNP (Fig. 8a), suggesting a response of Rossby waves in the lowlevel atmosphere to El Niño SSTA forcing (Wang et al. 2000; Wu et al. 2010; Stuecker et al. 2015). This broad-scale anticyclone centered at the central-southern SCS significantly reduces the total cloud cover over the southwestern SCS by suppressing local convection (Fig. 8a), corresponding to the enhanced mixed layer ocean temperature tendency (Fig. 8b) due to the increased net surface heat flux term (Fig. 8c). This anticyclonic anomaly directly leads to an increased net 
(a) Total duration

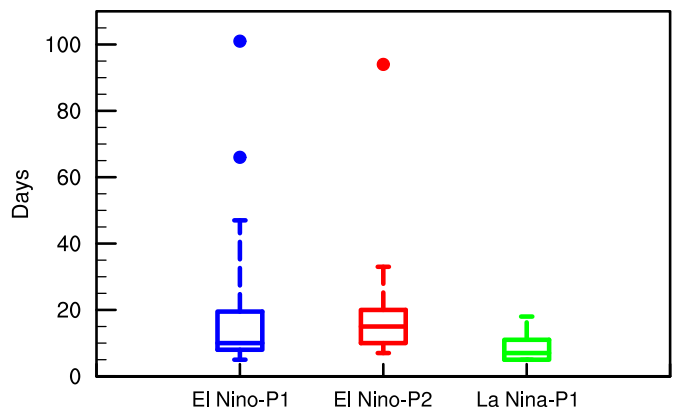

(c) Cumulative intensity

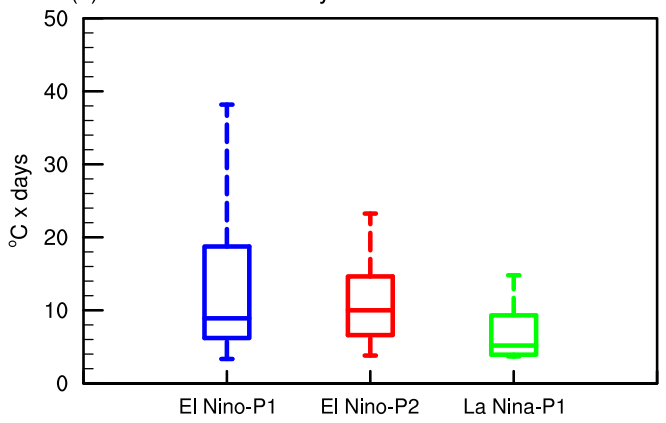

(b) Max intensity

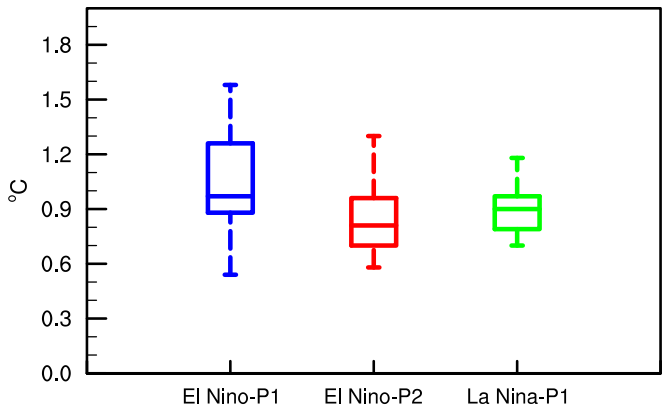

(d) Rate of growth

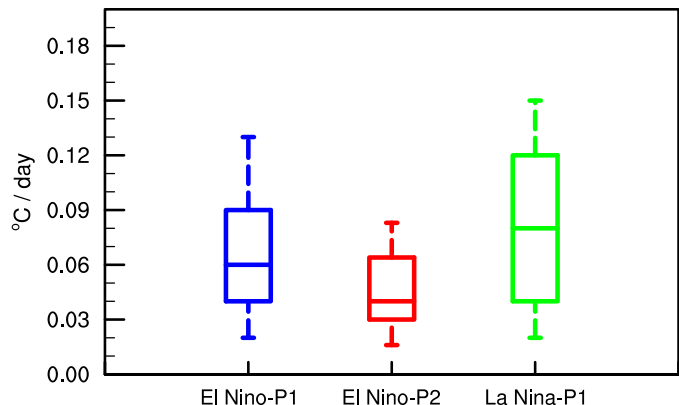

FIG. 5. As in Fig. 2, but for El Niño-P1, El Niño-P2, and La Niña-P1.

downward SWR over the southern SCS (Fig. 8d), and the significant southerly anomalies over the northern SCS reduce the total wind speed and associated surface evaporation over the WNP and SCS, which in turn results in a positive LHF anomaly over the northern SCS (Fig. 8e). The LHF is generally controlled by the surface wind speed and air-sea specific humidity difference (Chou et al. 2000), but Tan et al. (2016) revealed that surface speed anomalies are a predominant factor in LHF anomalies over the SCS. The spatial distribution of the net surface heat flux anomaly basically matches the mixed layer temperature tendency (Figs. 8b,c), and their corresponding centers are very consistent with the warming center of MHW-related SSTAs (Fig. 6a). Therefore, in El Niño$\mathrm{P} 1$, MHWs in the SCS are jointly contributed by the net
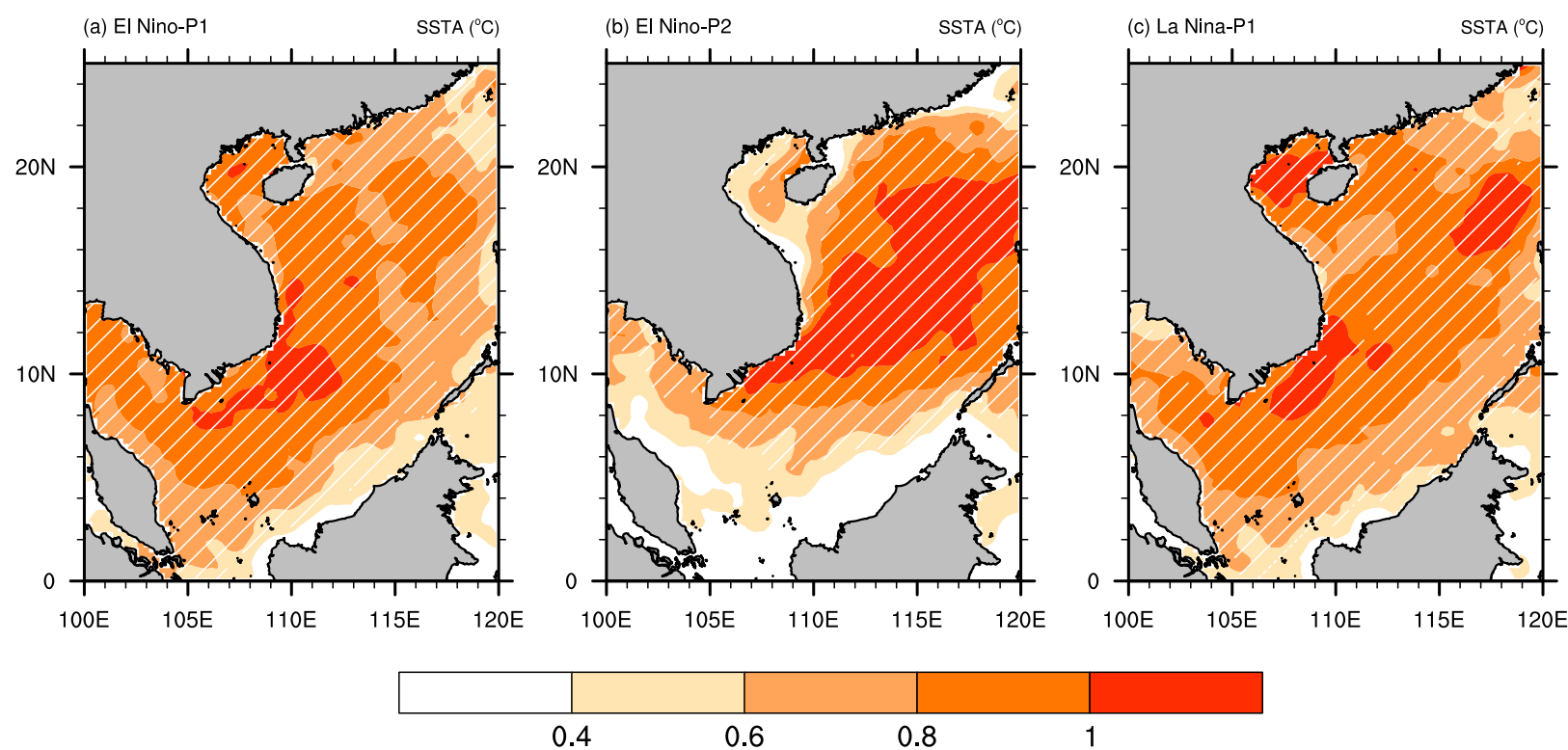

FIG. 6. Composite daily SSTAs (shading; ${ }^{\circ} \mathrm{C}$ ) in the SCS for MHW events in (a) El Niño-P1, (b) El Niño-P2, and (c) La Niña-P1. White oblique lines denote SSTAs that are above the $90 \%$ significance level. 
(a) Composite heat budget

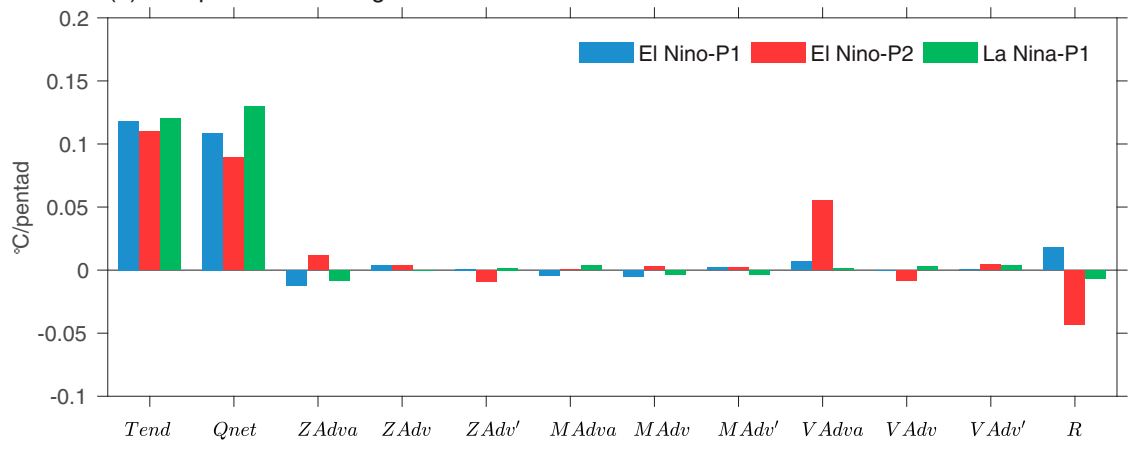

(b) Anomalous net surface heat flux terms

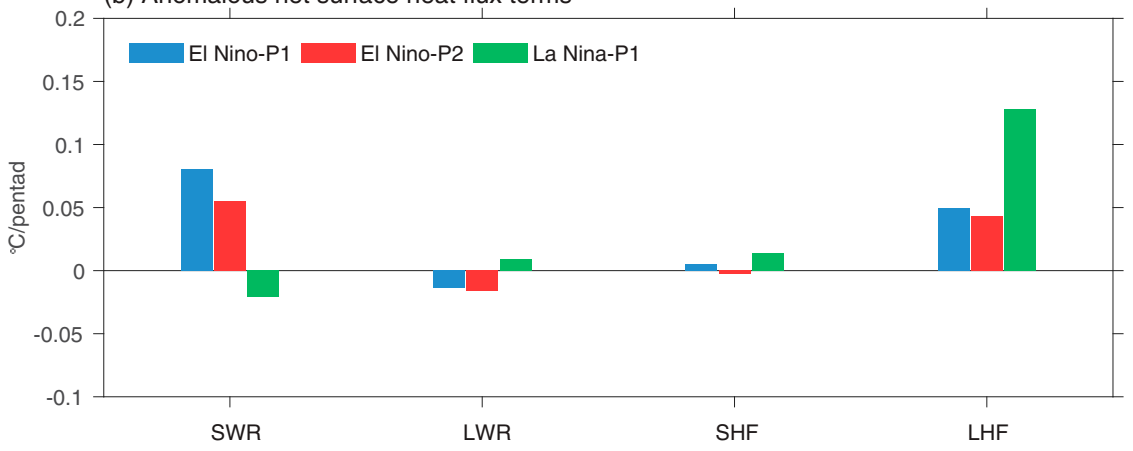

FIG. 7. (a) Composite of the mixed layer temperature tendency (Tend), the net surface heat flux term (Qnet), and the individual zonal, meridional, and vertical advection terms (unit: ${ }^{\circ} \mathrm{C}$ pentad $\left.^{-1}\right)$ averaged over the SCS $\left(0^{\circ}-25^{\circ} \mathrm{N}, 100^{\circ}-120^{\circ} \mathrm{E}\right)$ during the growth period of MHWs occurring in El Niño-P1, El Niño-P2, and La Niña-P1. (b) As in (a), but for the composite of four anomalous heat flux terms (unit: ${ }^{\circ} \mathrm{C}$ pentad ${ }^{-1}$ ) including the net downward shortwave radiation (SWR), net upward longwave radiation (LWR), sensible heat flux (SHF), and latent heat flux (LHF).

downward SWR over the southwestern SCS and the LHF anomalies over the northern SCS due to the enhanced WNP anticyclone. This mechanism responsible for SCS MHWs in El Niño-P1 is consistent with that responsible for the first SCS SST warming peak induced by El Niño (Wang et al. 2006).

In El Niño-P2, the enhanced WNP anticyclone is still dominant over the WNP because of the joint impacts of the local airsea interaction (Wang et al. 2000) and Indian Ocean capacitor effect (Xie et al. 2009), but its center shifts to the northern SCS due to the seasonal evolution of the East Asian summer monsoon. This anticyclone suppresses convective activity over the SCS and then effectively reduces the total cloud cover (Fig. 9a), leading to an increase in the net downward SWR in the central SCS (Fig. 9d). The lower-level northeasterly wind anomalies over the southern SCS weaken the summer monsoon winds, and the reduced surface wind speeds and associated surface evaporation give rise to an increase in the LHF anomaly in situ (Fig. 9e). Therefore, the net surface heat flux term during El Niño-P2 (Fig. 9c) is also attributed to both the net downward SWR anomaly over the central SCS (Fig. 9d) and the LHF anomaly over the southern SCS (Fig. 9e). However, we found that the increased net surface heat flux term cannot completely correspond to the warming SSTA centers of MHWs in El Niño-P2 (Fig. 6b) or the enhanced mixed layer ocean temperature (Fig. 9b), especially in the northern SCS. This result implies that the positive net surface heat flux term is a weak factor in the temperature tendency due to the shift in the net surface heat flux anomaly over the SCS (Figs. 9b,c), although it has a warming effect (Fig. 7a).

In addition, advections of the mean temperature by the anomalous vertical velocity and zonal velocity (i.e., VAdva and ZAdva) also make larger contributions to MHWs in the SCS (Fig. 7a). Figure 10 shows the spatial distribution of VAdva and ZAdva in El Niño-P2. In association with the narrow-scale anticyclone centered on the SCS (Fig. 9a), the surface wind stress curl over the central-northern SCS gives rise to enhanced convergence of the Ekman flows and induced Ekman downwelling in situ in El Niño-P2, resulting in the significant positive VAdva centered at $15^{\circ} \mathrm{N}, 114^{\circ} \mathrm{E}$ (Fig. 10a). Notably, the maximum VAdva values are in accordance with those of the positive temperature tendency and MHWs in the central-northern SCS (Figs. 6b and 9b). This finding indicates that the advection of the mean temperature by the anomalous vertical velocity provides the largest contribution to the growth of SCS MHWs in El Niño-P2. On the other hand, ZAdva makes a partially positive contribution to MHWs in the SCS due to the intensified SCS throughflow during El 
(a) $10 \mathrm{~m}$ Wind $(\mathrm{m} / \mathrm{s})$ \& TCC (\%) [El Nino-P1]

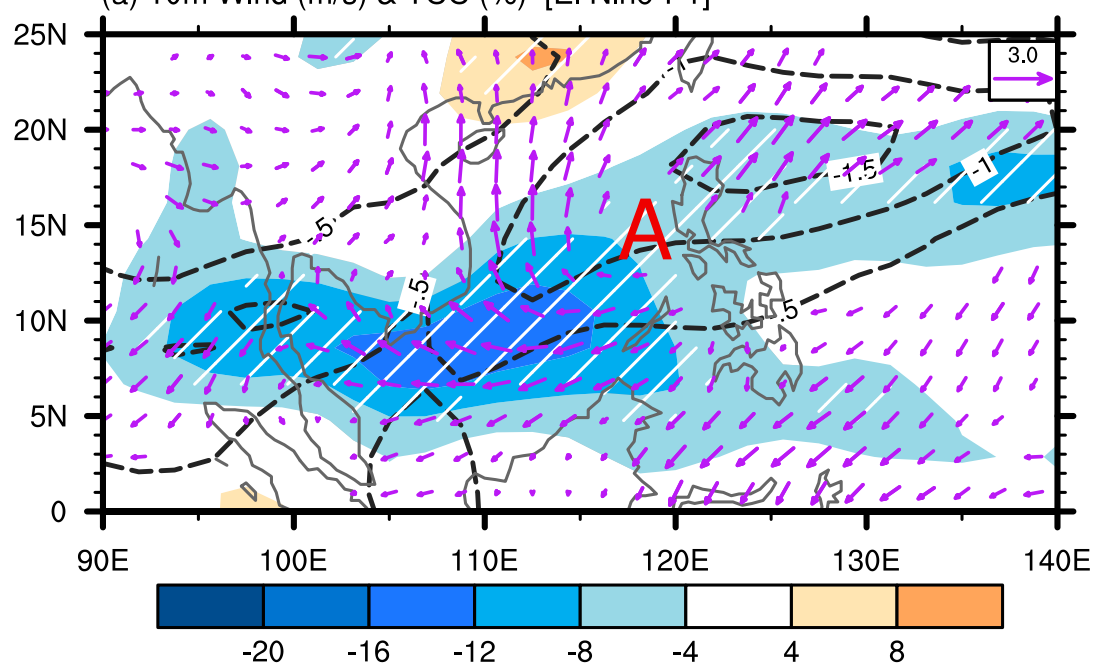

(c) Qnet

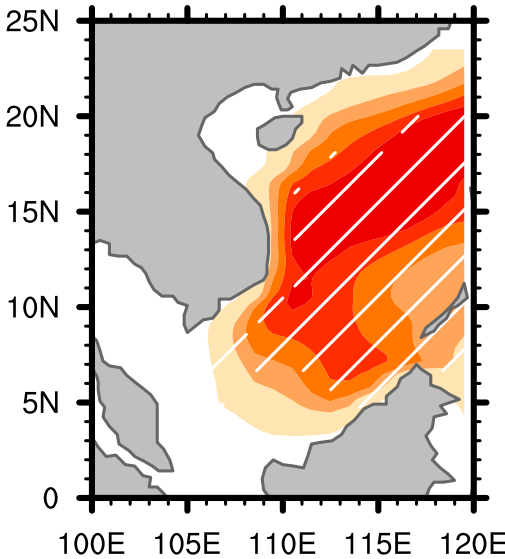

(d) SWR

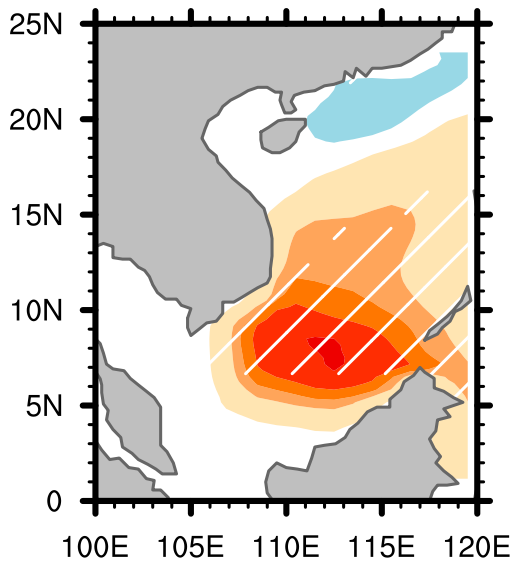

(b) Tend

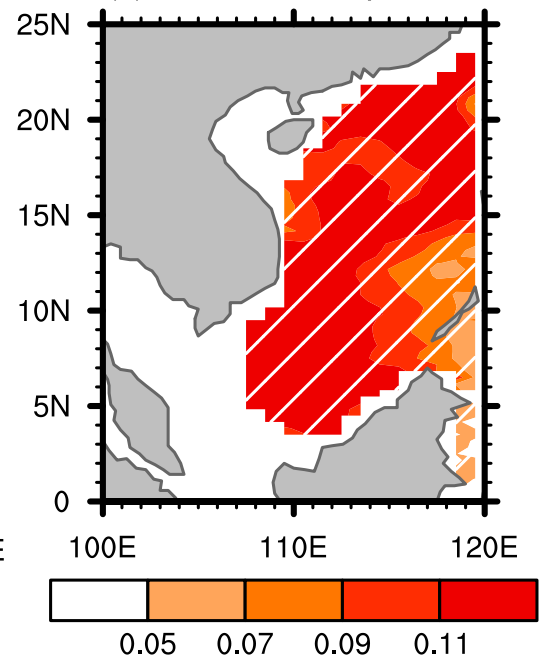

(e) LHF

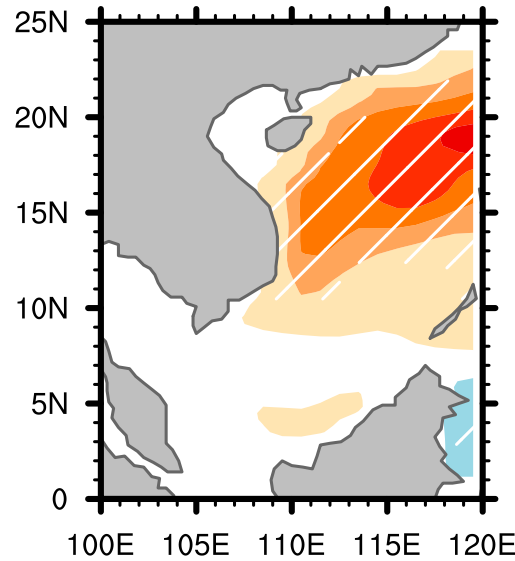

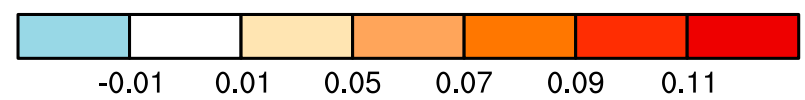

FIG. 8. (a) Composite wind (vectors; $\mathrm{m} \mathrm{s}^{-1}$ ) and wind speed (contours; $\mathrm{m} \mathrm{s}^{-1}$ ) at $10 \mathrm{~m}$ and total cloud cover (TCC; shading; \%) in the MHW growth period during El Niño-P1. Only wind speeds with values less than $-0.5 \mathrm{~m} \mathrm{~s}$ are shown, and purple wind vectors indicate that the $10-\mathrm{m}$ wind is above the $90 \%$ significance level. The red letter A indicates the center of the anomalous anticyclone. Also shown are composites of the (b) mixed layer ocean temperature tendency (Tend; ${ }^{\circ} \mathrm{C}$ pentad $\left.{ }^{-1}\right)$, (c) net surface heat flux term $\left(\mathrm{Qnet} ;{ }^{\circ} \mathrm{C}\right.$ pentad ${ }^{-1}$ ), (d) net downward SWR term $\left({ }^{\circ} \mathrm{C}\right.$ pentad $\left.{ }^{-1}\right)$, and (e) LHF term $\left({ }^{\circ} \mathrm{C}\right.$ pentad ${ }^{-1}$ ) over the SCS during the growth period of MHWs occurring in El Niño-P1. White oblique lines indicate values that are above the $90 \%$ significance level.

Niño (Liu et al. 2006), but it exhibits different effects in different SCS regions, with significant warming effects in the central SCS (Fig. 10b). This finding implies that the ZAdva term in the central SCS plays a partial role in the warming of MHWrelated SSTAs. Therefore, the ocean dynamic process (VAdva) related to Ekman downwelling plays an important role in SCS MHWs in El Niño-P2, whereas the atmospheric thermodynamic process becomes less important, albeit with a warming effect. Wang et al. (2006) also emphasized the role of ocean dynamic processes in the second peak of SCS warming, but they revealed that mean meridional geostrophic heat advection is responsible for SCS SSTA warming.

During La Niña-P1, a weaker lower-level WNP anticyclone is observed east of the Philippines, although the magnitude and northeastward displacement of the center location are weaker than those in El Niño-P1 (Fig. 11a). The significant southerly wind anomalies weaken the climatological northeasterly wind, subsequently reducing the surface wind speed and evaporation in situ and enhancing the ocean temperature 
(a) $10 \mathrm{~m}$ Wind $(\mathrm{m} / \mathrm{s})$ \& TCC (\%) [El Nino-P2]

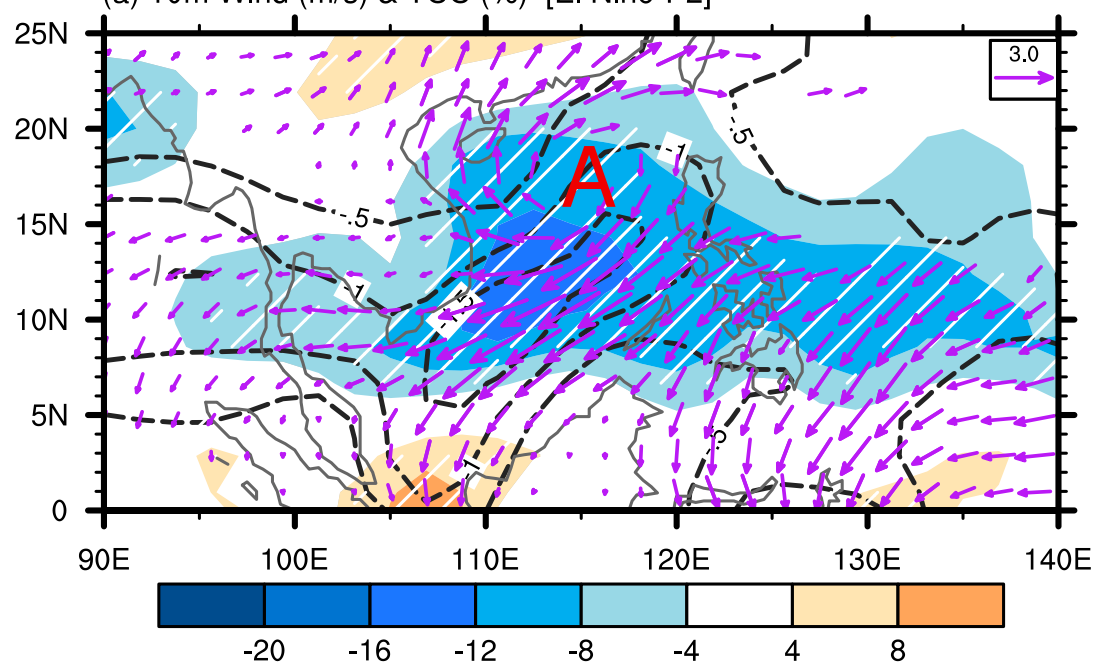

(c) Qnet

${ }^{\circ} \mathrm{C} /$ pentad

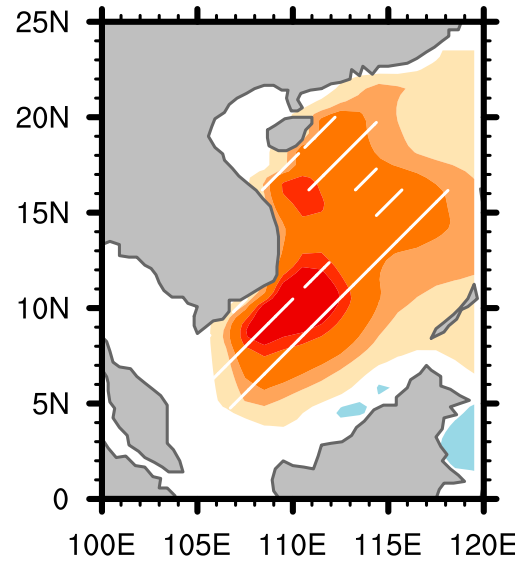

(d) SWR

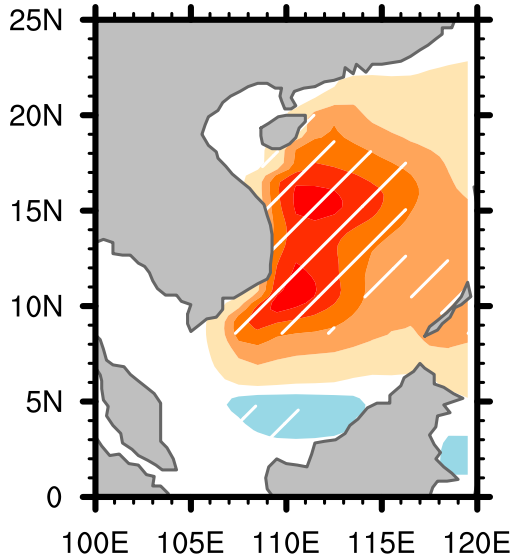

(b) Tend

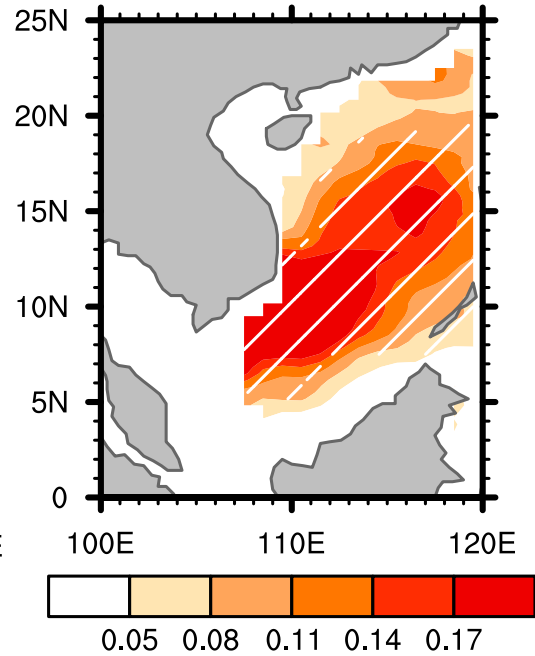

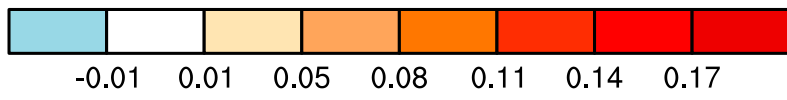

(e) LHF

${ }^{\circ} \mathrm{C} /$ pentad

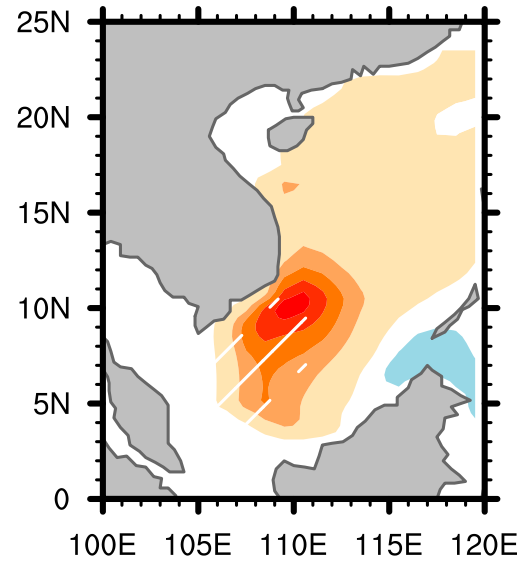

FIG. 9. As in Fig. 8, but for El Niño-P2.

tendency over the central-northern SCS (Fig. 11b). The increased net surface heat flux term (Fig. 11c) is contributed less by the SWR anomaly (Fig. 11d) and mostly comes from the LHF anomaly (Fig. 11e). Different from the other categories, the SHF plays a partial role in local thermodynamic heating (not shown), but the warming effect of the net downward SWR is almost negligible (Fig. 11d).

During the spring of decaying La Niña events, an anomalous lower-level cyclone is usually found over the WNP (Zhang et al. 2014; Chen et al. 2016). However, a relatively weak anomalous anticyclone can be observed based on the pentad-data analysis in the case of La Niña-P1 (Fig. 11a), and the observed SCS MHWs in La Niña-P1 exhibit a short life cycle of less than 10 days (Fig. 5a). This possibly originates from suppressed convection and weak intraseasonal oscillation (ISO) activity (Zhang et al. 2014). We also found that SCS MHWs in La Niña-P1 are usually associated with suppressed convection and the inactive phase of the MaddenJulian oscillation (MJO), which implies that an anomalous WNP anticyclone with suppressed convection in relation to the inactive phase of the MJO plays a critical role in the occurrence of short-lived SCS MHWs in La Niña-P1 (not shown). Because of the longer duration (approximately 20 days) of $\mathrm{MHWs}$ in $\mathrm{El}$ Niño-P1 and El Niño-P2, the response of the anomalous WNP anticyclone to El Niño can be well reproduced by monthly data analyses (not shown). 
(a) VAdva

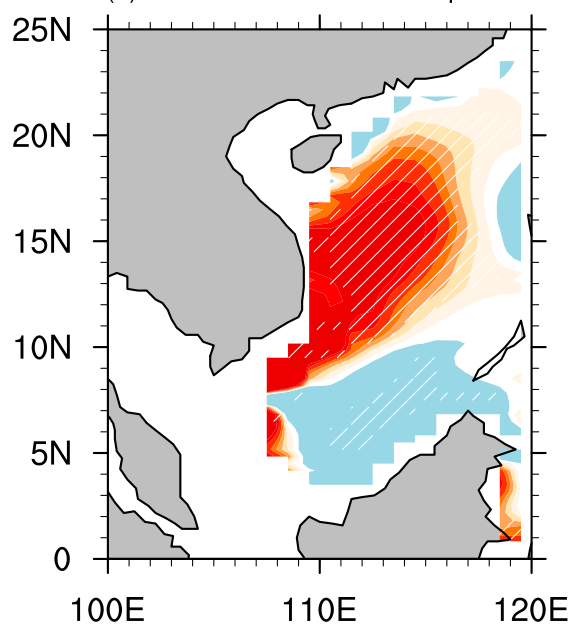

(b) ZAdva

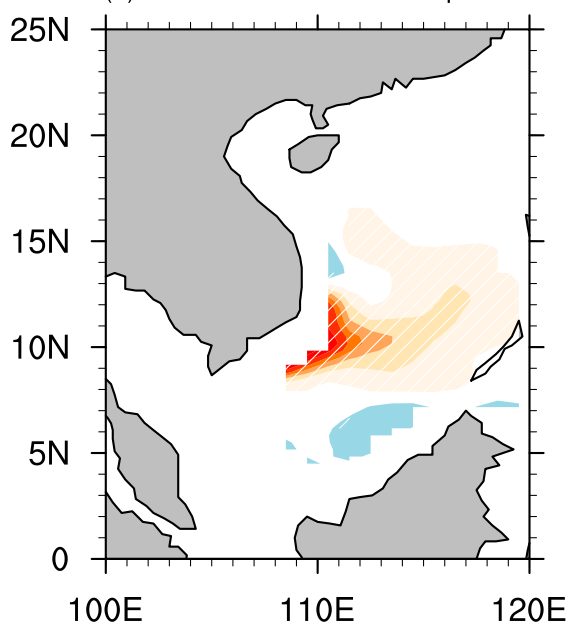

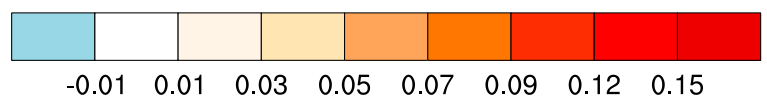

FIG. 10. Composite (a) vertical advection of the mean temperature by the anomalous vertical velocity (VAdva; ${ }^{\circ} \mathrm{C}$ pentad ${ }^{-1}$ ) and (b) zonal advection of the mean temperature by the anomalous zonal velocity (ZAdva; ${ }^{\circ} \mathrm{C}$ pentad ${ }^{-1}$ ) over the SCS during the growth period of MHWs occurring in El Niño-P2. White oblique lines indicate values above the $90 \%$ significance level.

\section{Summary and discussion}

Based on the definition of MHWs by Hobday et al. (2016), we investigate MHWs in the SCS during 1982-2018 and discuss their diversity and physical mechanisms linked with the ENSO phase. Our results show that most MHWs increased after 1996 under the warming trend of the SCS SST. Statistical analyses show that the occurrence of SCS MHWs exhibits pronounced seasonal fluctuations. During the boreal summer and winter, MHWs are stronger than their spring and autumn counterparts. Moreover, MHWs with stronger cumulative intensities generally develop more slowly and last longer, and vice versa.

SCS MHWs exhibit seasonal phase locking with double and single warming peaks induced by El Niño and La Niña events, respectively. The varied seasonal ENSO-induced warming SSTA provides a favorable background and results in the diversity of SCS MHWs. According to their warming peaks, SCS MHWs can be categorized into three types, namely, El Niño$\mathrm{P} 1$, corresponding to the first warming peak in El Niño from September to the following February, El Niño-P2, occurring during the second warming peak in El Niño from the following June to September, and La Niña-P1, appearing under the warming peak in La Niña during the following February to May. The warming SSTA center of the SCS is located in the southwestern and central-northern SCS in El Niño-P1 and El Niño-P2, respectively, while significant warming SSTAs are observed in the Beibu Gulf, west of the Luzon Strait, and along the Vietnam coast in La Niña-P1.

Based on the mixed layer heat budget analysis, our results show that in El Niño-P1, SCS MHWs can be mainly attributed to the joint effects of the net downward SWR and LHF anomalies. In El Niño-P2, the advection of the mean temperature by the anomalous vertical velocity plays a crucial role in the warming SSTA growth rate of SCS MHWs, despite being the second largest contributor to the mixed layer tendency over the entire SCS. The largest contributor to MHWs in La NiñaP1 is the LHF anomaly. Therefore, both El Niño and La Niña events can remarkably modulate SCS MHWs through atmospheric and oceanic conditions and air-sea interactions in the SCS. The enhanced lower-level WNP anticyclone plays a crucial role in the occurrence of SCS MHWs. The physical mechanisms of SCS MHW regulation by ENSO can be summarized in a schematic diagram (Fig. 12).

During El Niño-P1, El Niño can induce lower-level anticyclonic wind anomalies over a broad region from the IndoChina Peninsula to the WNP via the Rossby wave response. This anticyclone, which is centered in the central-southern SCS, significantly reduces the total cloud cover over the southwestern SCS and then enhances the net downward SWR in situ. On the other hand, the southerly anomalies over the northern SCS are in the opposite direction to the climatological near-surface northeasterly anomalies and thus reduce the total wind speed and associated surface evaporation, leading to an increase in the LHF anomaly in the northern SCS (Fig. 12a). As a result, both the enhanced net downward SWR over the southwestern SCS and the reduced LHF loss over the northern SCS, which are associated with the El Niño-induced anticyclone anomaly, play a joint fundamental role in the onset of SCS MHWs. In contrast, although the net downward SWR and LHF have warming effects, they only play partial 
(a) $10 \mathrm{~m}$ Wind $(\mathrm{m} / \mathrm{s}) \&$ TCC (\%) [La Nina-P1]

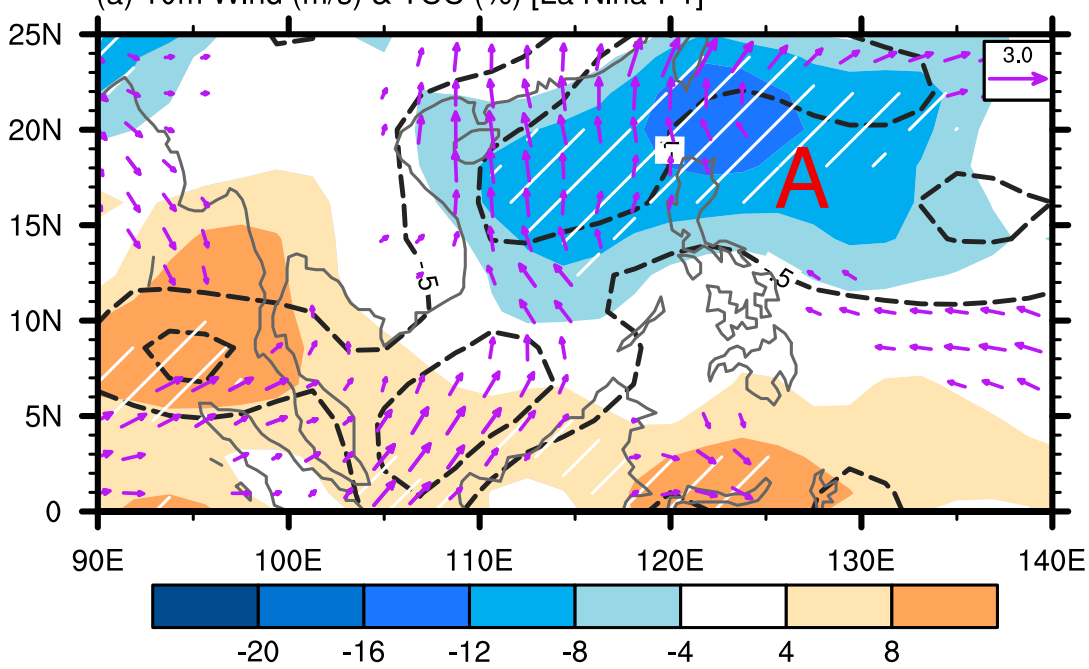

(c) Qnet

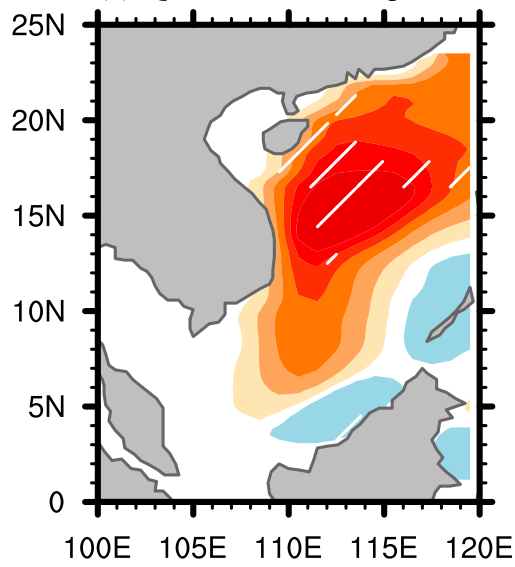

(d) SWR

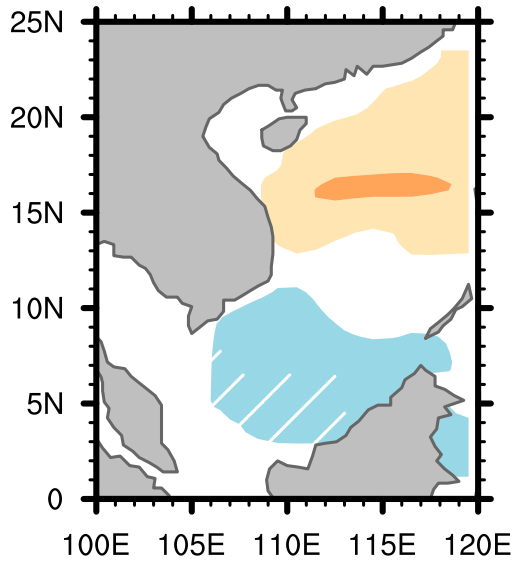

100 $105 \mathrm{E} \quad 110 \mathrm{E} \quad 115 \mathrm{E} \quad 120 \mathrm{E}$ (b) Tend

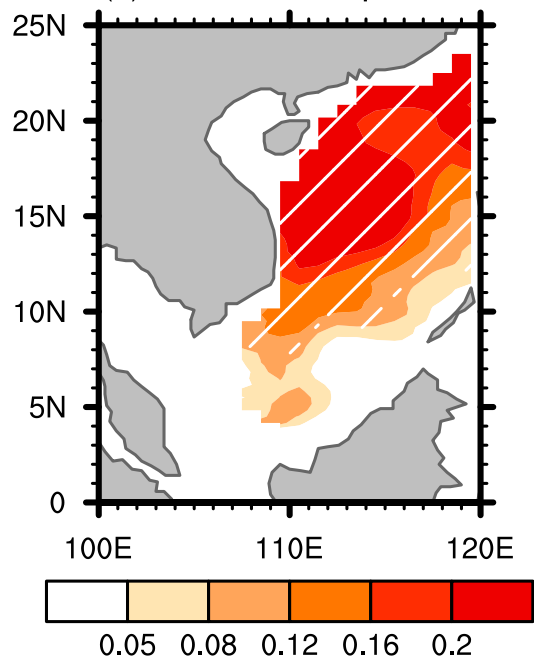

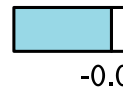

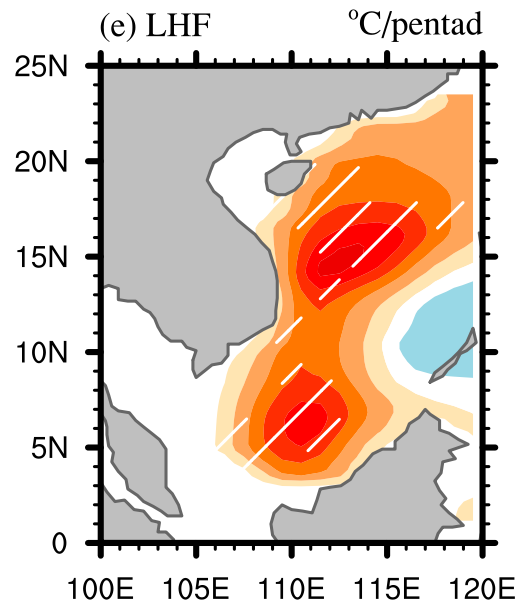

01

$\begin{array}{lllll}0.01 & 0.04 & 0.08 & 0.12 & 0.16\end{array}$

0.2

FIG. 11. As in Fig. 8, but for La Niña-P1.

roles in SCS MHWs in El Niño-P2. An anomalous anticyclone exists in E1 Niño-P2 but is confined to more northern latitudes near the northern SCS. This small-scale anticyclone induces Ekman convergence and in turn enhances Ekman downwelling in the central-northern SCS, finally favoring the formation and development of MHWs in situ (Fig. 12b). Thus, SCS MHWs in El Niño-P2 are mainly attributed to the advection of the mean temperature by the anomalous vertical velocity. During La Niña-P1, the enhanced LHF anomaly over the SCS, which is caused by a weak anomalous lower-level anticyclone centered east of the Philippines related to the inactive MJO during the spring following La Niña, is the dominant factor that contributes to MHWs over the central-northern SCS (Fig. 12c).
Here, we only emphasize the mechanisms of SCS MHWs under the impact of ENSO events. Notably, the responses of SCS SSTAs and WNP atmospheric circulation anomalies to different types of ENSO events are significantly different (Wang et al. 2006; Tan et al. 2016; Xu et al. 2013, 2019a). More work needs to be done to understand the possible different responses of SCS MHWs to ENSO diversity. In fact, nine SCS MHW events cannot be attributed to the impact of ENSO phases, indicating that SCS MHWs may be modulated by other factors, such as the Pacific western boundary currents (Xiao et al. 2018), the unusual Indian Ocean dipole (Xiao et al. 2020), the interbasin interactions (Yao and Wang 2021), and global warming (Oliver 2019). Moreover, we speculated that the ISO over the WNP could affect SCS MHWs in 


\section{(a) El Niño-P1}

(b) EI Niño-P2

(c) La Niña-P1

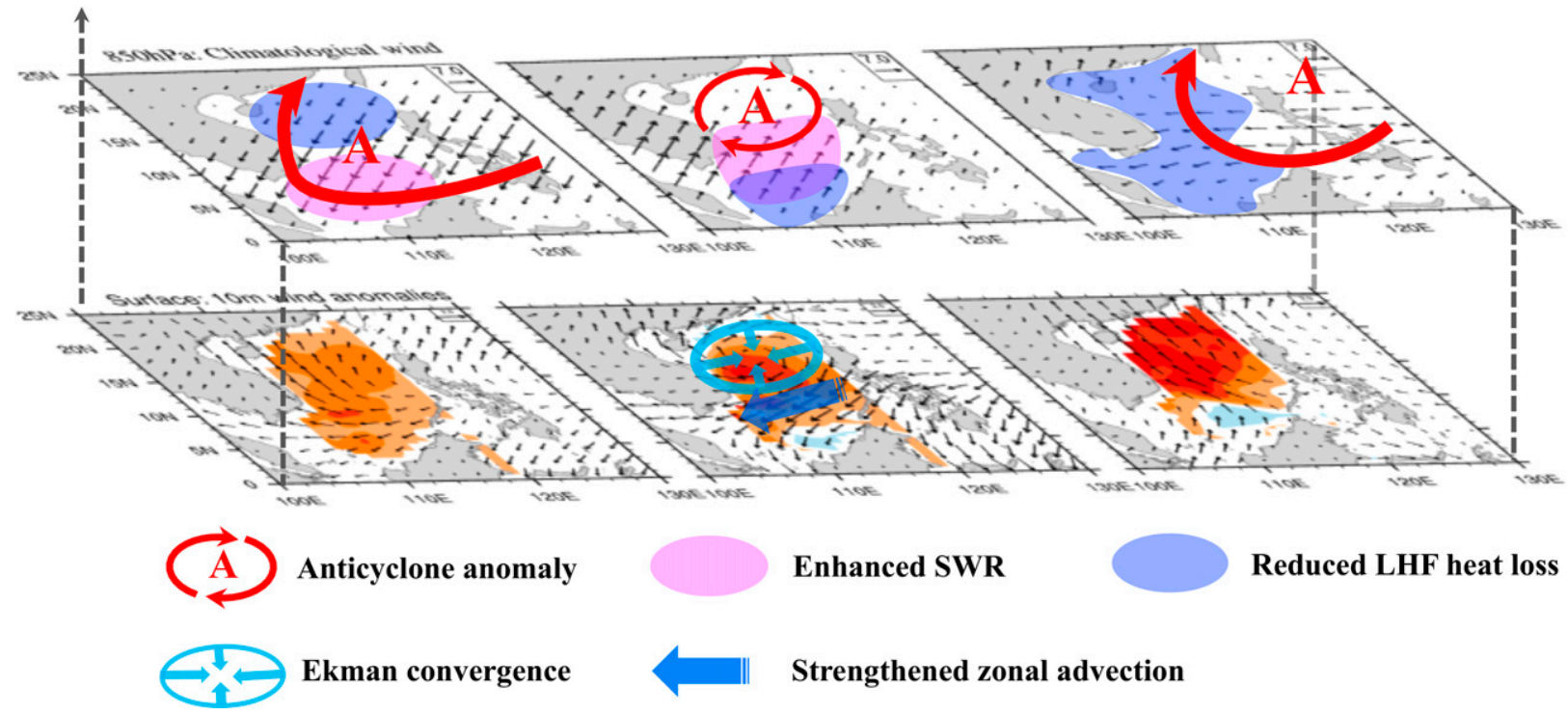

FIG. 12. Schematic diagram illustrating the potential physical mechanisms associated with ENSO influencing SCS MHWs. (top) Climatological wind at $850 \mathrm{hPa}$ (vectors) in (a) El Niño-P1, (b) El Niño-P2, and (c) La Niña-P1 and (bottom) wind anomalies at $10 \mathrm{~m}$ (vectors) and the mixed layer ocean temperature tendency (shading) over the SCS during the growth period of SCS MHWs.

La Niña-P1. Thus, the coeffect of multiple factors on MHWs in the SCS merits further study. In addition, our results are primarily obtained from statistical analyses and pentad-scale datasets; therefore, the dynamics and thermodynamics of MHWs in the SCS require a modeling study with high spatial and temporal resolutions.

Acknowledgments. This work is jointly sponsored by the National Key R\&D Program of China (2019YFA0606701), the National Natural Science Foundation of China (41830969, 42076020, and 41776023), the Youth Innovation Promotion Association CAS (2020340), the Rising Star Foundation of the SCSIO (NHXX2018WL0201), the Key Special Project for Introduced Talents Team of Southern Marine Science and Engineering Guangdong Laboratory (Guangzhou) (GML2019ZD0306), the Innovation Academy of South China Sea Ecology and Environmental Engineering, CAS (ISEE2021ZD01), and the Independent Research Project Program of State Key Laboratory of Tropical Oceanography (LTOZZ2101).

Data availability statement. The NOAA daily OISST V2 dataset is available at https://psl.noaa.gov/data/gridded/data.noaa. oisst.v2.highres.html. The daily NCEP-DOE R2 data are obtained from https://psl.noaa.gov/data/gridded/data.ncep.reanalysis $2 . h t m l$. The pentad GODAS data are available at https://www.cpc.ncep. noaa.gov/products/GODAS.

\section{REFERENCES}

Behringer, D. W., 2007: The Global Ocean Data Assimilation System (GODAS) at NCEP. 11th Symp. on Integrated Observing and Assimilation Systems for Atmosphere, Oceans, and Land Surface, San Antonio, TX, Amer. Meteor. Soc.,
3.3, https://ams.confex.com/ams/87ANNUAL/techprogram/ paper_119541.htm.

Benthuysen, J. A., E. C. J. Oliver, M. Feng, and A. G. Marshall, 2018: Extreme marine warming across tropical Australia during austral summer 2015-2016. J. Geophys. Res. Oceans, 123, 1301-1326, https://doi.org/10.1002/2017JC013326.

Bond, N. A., M. F. Cronin, H. Freeland, and N. Mantua, 2015: Causes and impacts of the 2014 warm anomaly in the NE Pacific. Geophys. Res. Lett., 42, 3414-3420, https://doi.org/10. 1002/2015GL063306.

Caputi, N., M. Kangas, A. Denham, M. Feng, A. Pearce, Y. Hetzel, and A. Chandrapavan, 2016: Management adaptation of invertebrate fisheries to an extreme marine heat wave event at a global warming hot spot. Ecol. Evol., 6, 3583-3593, https://doi.org/10.1002/ece3.2137.

Chen, G., and H. Qin, 2016: Strong ocean-atmosphere interactions during a short-term hot event over the western Pacific warm pool in response to El Niño. J. Climate, 29, 3841-3865, https://doi.org/10.1175/JCLI-D-15-0595.1.

Chen, Z., Z. Wen, R. Wu, and Y. Du, 2016: Roles of tropical SST anomalies in modulating the western North Pacific anomalous cyclone during strong La Niña decaying years. Climate Dyn., 49, 633-647, https://doi.org/10.1007/s00382-016-3364-4.

Chou, S.-H., W. Zhao, and M.-D. Chou, 2000: Surface heat budgets and sea surface temperature in the Pacific warm pool during TOGA COARE. J. Climate, 13, 634-649, https://doi.org/ 10.1175/1520-0442(2000)013<0634:SHBASS > 2.0.CO;2.

Di Lorenzo, E., and N. Mantua, 2016: Multi-year persistence of the 2014/15 North Pacific marine heatwave. Nat. Climate Change, 6, 1042-1047, https://doi.org/10.1038/nclimate3082.

Feng, M., M. J. McPhaden, S. Xie, and J. Hafner, 2013: La Niña forces unprecedented Leeuwin Current warming in 2011. Sci. Rep., 3, 1277, https://doi.org/10.1038/srep01277.

Frolicher, T. L., and C. Laufkotter, 2018: Emerging risks from marine heat waves. Nat. Commun., 9, 650, https://doi.org/10. 1038/s41467-018-03163-6. 
- E. M. Fischer, and N. Gruber, 2018: Marine heatwaves under global warming. Nature, 560, 360-364, https://doi.org/ 10.1038/s41586-018-0383-9.

Gao, G., M. Marin, M. Feng, B. Yin, D. Yang, X. Feng, Y. Ding, and D. Song, 2020: Drivers of marine heatwaves in the East China Sea and the South Yellow Sea in three consecutive summers during 2016-2018. J. Geophys. Res. Oceans, 125, e2020JC016518, https://doi.org/10.1029/2020JC016518.

Garrabou, J., and Coauthors, 2009: Mass mortality in northwestern Mediterranean rocky benthic communities: Effects of the 2003 heat wave. Global Change Biol., 15, 1090-1103, https:// doi.org/10.1111/j.1365-2486.2008.01823.x.

Heidemann, H., and J. Ribbe, 2019: Marine heat waves and the influence of El Niño off southeast Queensland, Australia. Front. Mar. Sci., 6, 56, https://doi.org/10.3389/fmars.2019. 00056.

Hobday, A. J., and Coauthors, 2016: A hierarchical approach to defining marine heatwaves. Prog. Oceanogr., 141, 227-238, https://doi.org/10.1016/j.pocean.2015.12.014.

Holbrook, N. J., and Coauthors, 2019: A global assessment of marine heatwaves and their drivers. Nat. Commun., 10, 2624, https://doi.org/10.1038/s41467-019-10206-z.

- A. Sen Gupta, E. C. J. Oliver, A. J. Hobday, J. A. Benthuysen, H. A. Scannell, D. A. Smale, and T. Wernberg, 2020: Keeping pace with marine heatwaves. Nat. Rev. Earth Environ., 1, 482-493, https://doi.org/10.1038/s43017-020-0068-4.

Kanamitsu, M., W. Ebisuzaki, J. Woollen, S.-K. Yang, J. J. Hnilo, M. Fiorino, and G. L. Potter, 2002: NCEP-DOE AMIP-II Reanalysis (R-2). Bull. Amer. Meteor. Soc., 83, 1631-1644, https://doi.org/10.1175/BAMS-83-11-1631.

Klein, S. A., B. J. Soden, and N.-C. Lau, 1999: Remote sea surface temperature variations during ENSO: Evidence for a tropical atmospheric bridge. J. Climate, 12, 917-932, https://doi.org/10. 1175/1520-0442(1999)012<0917:RSSTVD > 2.0.CO;2.

Li, Y., G. Ren, Q. Wang, and Q. You, 2019: More extreme marine heatwaves in the China Seas during the global warming hiatus. Environ. Res. Lett., 14, 104010, https://doi.org/10. 1088/1748-9326/ab28bc.

Li, Z., N. J. Holbrook, X. Zhang, E. C. J. Oliver, and E. A. Cougnon, 2020: Remote forcing of Tasman Sea marine heatwaves. J. Climate, 33, 5337-5354, https://doi.org/10.1175/JCLI-D-190641.1.

Liu, Q.-Y., R. X. Huang, D. X. Wang, Q. Xie, and Q. Z. Huang, 2006: Interplay between the Indonesian throughflow and the South China Sea throughflow. Chin. Sci. Bull., 51, 50-58, https://doi.org/10.1007/s11434-006-9050-x.

- D. Wang, X. Wang, Y. Shu, Q. Xie, and J. Chen, 2014: Thermal variations in the South China Sea associated with the eastern and central Pacific El Niño events and their mechanisms. J. Geophys. Res. Oceans, 119, 8955-8972, https:// doi.org/10.1002/2014JC010429.

Mills, K., and Coauthors, 2013: Fisheries management in a changing climate: Lessons from the 2012 ocean heat wave in the northwest Atlantic. Oceanography, 26, 191-195, https://oi. org/10.5670/oceanog.2013.27.

Olita, A., R. Sorgente, S. Natale, S. Gabersek, A. Ribotti, A. Bonanno, and B. Patti, 2007: Effects of the 2003 European heatwave on the central Mediterranean Sea: Surface fluxes and the dynamical response. Ocean Sci., 3, 273-289, https:// doi.org/10.5194/os-3-273-2007.

Oliver, E. C. J., 2019: Mean warming not variability drives marine heatwave trends. Climate Dyn., 53, 1653-1659, https://doi.org/ 10.1007/s00382-019-04707-2.
—, J. A. Benthuysen, N. L. Bindoff, A. J. Hobday, N. J. Holbrook, C. N. Mundy, and S. E. Perkins-Kirkpatrick, 2017: The unprecedented 2015/16 Tasman Sea marine heatwave. Nat. Commun., 8, 16101, https://doi.org/10.1038/ncomms16101.

— , V. Lago, A. J. Hobday, N. J. Holbrook, S. D. Ling, and C. N. Mundy, 2018a: Marine heatwaves off eastern Tasmania: Trends, interannual variability, and predictability. Prog. Oceanogr., 161, 116-130, https://doi.org/10.1016/j.pocean.2018.02. 007.

— , and Coauthors, 2018b: Longer and more frequent marine heatwaves over the past century. Nat. Commun., 9, 1324, https://doi.org/10.1038/s41467-018-03732-9.

Ose, T., Y. Song, and A. Kitoh, 1997: Sea surface temperature in the South China Sea: An index for the Asian monsoon and ENSO system. J. Meteor. Soc. Japan, 75, 1091-1107, https:// doi.org/10.2151/jmsj1965.75.6_1091.

Pearce, A. F., and M. Feng, 2013: The rise and fall of the "marine heat wave" off Western Australia during the summer of 2010/2011. J. Mar. Syst., 111-112, 139-156, https://doi.org/10. 1016/j.jmarsys.2012.10.009.

Qin, H., and H. Kawamura, 2009: Surface heat fluxes during hot events. J. Oceanogr., 65, 605-613, https://doi.org/10.1007/ s10872-009-0051-7.

- , and - 2010: Air-sea interaction throughout the troposphere over a very high sea surface temperature phenomenon. Geophys. Res. Lett., 37, L01704, https://oi.org/10.1029/ 2009GL041685.

- - , and Y. Kawai, 2007: Detection of hot event in the equatorial Indo-Pacific warm pool using advanced satellite sea surface temperature, solar radiation, and wind speed. J. Geophys. Res., 112, C07015, https://doi.org/10.1029/2006JC003969.

_ - F. Sakaida, and K. Ando, 2008: A case study of the tropical hot event in November 2006 (HE0611) using a geostationary meteorological satellite and the TAO/TRITON mooring array. J. Geophys. Res., 113, C08045, https://doi.org/10.1029/ 2007JC004640.

Qu, T., Y. Y. Kim, M. Yaremchuk, T. Tozuka, A. Ishida, and T. Yamagata, 2004: Can Luzon Strait Transport play a role in conveying the impact of ENSO to the South China Sea? J. Climate, 17, 3644-3657, https://doi.org/10.1175/ 1520-0442(2004)017\%3C3644:CLSTPA\%3E2.0.CO;2.

Reynolds, R. W., T. M. Smith, C. Liu, D. B. Chelton, M. G. Schlax, and K. S. Casey, 2007: Daily high-resolution-blended analyses for sea surface temperature. J. Climate, 20, 5473 5496, https://doi.org/10.1175/2007JCLI1824.1.

Scannell, H. A., A. J. Pershing, M. A. Alexander, A. C. Thomas, and K. E. Mills, 2016: Frequency of marine heatwaves in the North Atlantic and North Pacific since 1950. Geophys. Res. Lett., 43, 2069-2076, https://doi.org/10.1002/2015GL067308.

Schlegel, R. W., E. C. J. Oliver, S. Perkins-Kirkpatrick, A. Kruger, and A. J. Smit, 2017: Predominant atmospheric and oceanic patterns during coastal marine heatwaves. Front. Mar. Sci., 4, 323, https://doi.org/10.3389/fmars.2017.00323.

Smale, D. A., and Coauthors, 2019: Marine heatwaves threaten global biodiversity and the provision of ecosystem services. Nat. Climate Change, 9, 306-312, https://doi.org/10.1038/ s41558-019-0412-1.

Stuecker, M. F., A. Timmermann, F.-F. Jin, and S. McGregor, 2015: Combination mode dynamics of the anomalous northwest Pacific anticyclone. J. Climate, 28, 1093-1111, https://doi. org/10.1175/JCLI-D-14-00225.1.

Tan, W., X. Wang, W. Wang, C. Wang, and J. Zuo, 2016: Different responses of sea surface temperature in the South China Sea 
to various El Niño events during boreal autumn. J. Climate, 29, 1127-1142, https://doi.org/10.1175/JCLI-D-15-0338.1.

Thompson, B., P. Tkalich, and P. Malanotte-Rizzoli, 2017: Regime shift of the South China Sea SST in the late 1990s. Climate Dyn., 48, 1873-1882, https://doi.org/10.1007/s00382016-3178-4.

Waliser, D. E., 1996: Formation and limiting mechanisms for very high sea surface temperature: Linking the dynamics and the thermodynamics. J. Climate, 9, 161-188, https://doi.org/10. 1175/1520-0442(1996)009<0161:FALMFV>2.0.CO;2.

Wang, B., R. Wu, and X. Fu, 2000: Pacific-East Asian teleconnection: How does ENSO affect East Asian climate? J. Climate, 13, 1517-1536, https://doi.org/10.1175/1520-0442(2000)013<1517: PEATHD $>2.0 . \mathrm{CO} ; 2$.

Wang, C., W. Wang, D. Wang, and Q. Wang, 2006: Interannual variability of the South China Sea associated with El Niño. J. Geophys. Res., 111, C03023, https://doi.org/10.1029/2005JC003333.

Wang, Q., Y. Li, Q. Li, Y. Liu, and Y. Wang, 2019: Changes in means and extreme events of sea surface temperature in the East China Seas based on satellite data from 1982 to 2017. Atmosphere, 10, 140, https://doi.org/10.3390/atmos10030140.

Wu, B., T. Li, and T. Zhou, 2010: Asymmetry of atmospheric circulation anomalies over the western North Pacific between El Niño and La Niña. J. Climate, 23, 4807-4822, https://doi. org/10.1175/2010JCLI3222.1.

Xiao, F., L. Zeng, Q.-Y. Liu, W. Zhou, and D. Wang, 2018: Extreme subsurface warm events in the South China Sea during 1998/99 and 2006/07: Observations and mechanisms. Climate Dyn., 50, 115-128, https://doi.org/10.1007/s00382-0173588-y.

, D. Wang, and M. Y. T. Leung, 2020: Early and extreme warming in the south china sea during 2015/2016: Role of an unusual Indian Ocean Dipole event. Geophys. Res. Lett., 47, e2020GL089936, https://doi.org/10.1029/2020GL089936.
Xie, S.-P., T. Sampe, G. Huang, Y. Du, H. Tokinaga, J. Hafner, and $\mathrm{K}$. Hu, 2009: Indian Ocean capacitor effect on Indo-western Pacific climate during the summer following El Niño. $J$. Climate, 22, 730-747, https://doi.org/10.1175/2008JCLI2544.1.

Xu, K., C. Zhu, and J. He, 2013: Two types of El Niño-related Southern Oscillation and their different impacts on global land precipitation. Adv. Atmos. Sci., 30, 1743-1757, https:// doi.org/10.1007/s00376-013-2272-3.

- , Q.-L. Huang, C.-Y. Tam, W. Wang, S. Chen, and C. Zhu, 2019a: Roles of tropical SST patterns during two types of ENSO in modulating wintertime rainfall over southern China. Climate Dyn., 52, 523-538, https://doi.org/10.1007/s00382-018-4170-y.

— - W. Wang, B. Liu, and C. Zhu, 2019b: Weakening of the El Niño amplitude since the late 1990s and its link to decadal change in the North Pacific climate. Int. J. Climatol., 39, 4125-4138, https://doi.org/10.1002/joc.6063.

Yan, Y., F. Chai, H. Xue, and G. Wang, 2020: Record-breaking sea surface temperatures in the Yellow and East China Seas. J. Geophys. Res. Oceans, 125, e2019JC015883, https://doi.org/ 10.1029/2019JC015883.

Yao, Y., and C. Wang, 2021: Variations in summer marine heatwaves in the South China Sea. J. Geophys. Res. Oceans, 126, e2021JC017792, https://doi.org/10.1029/2021JC017792.

_ J. Wang, J. Yin, and X. Zou, 2020: Marine heatwaves in China's marginal seas and adjacent offshore waters: Past, present, and future. J. Geophys. Res. Oceans, 125, e2019JC015801, https://doi.org/10.1029/2019JC015801.

Zhang, R., T. Li, M. Wen, and L. Liu, 2014: Role of intraseasonal oscillation in asymmetric impacts of El Niño and La Niña on the rainfall over southern China in boreal winter. Climate Dyn., 45, 559-567, https://doi.org/10.1007/s00382014-2207-4. 